2

3

4

5

6

\title{
An Overview of Modification, Hybridization and Applications of Saponite
} (1) (1)

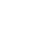
5

${ }^{a}$ Research Group for Advanced Materials \& Sustainable Catalysis (AMSC), State Key Laboratory Breeding Base of Green Chemistry-Synthesis Technology, College of Chemical Engineering, Zhejiang University of Technology, Hangzhou 310032, China

${ }^{b}$ Key Laboratory of Clay Minerals of Ministry of Land and Resources of the People's Republic of China, Engineering Research Center of Non-metallic Minerals of Zhejiang Province, Zhejiang Institute of Geology and Mineral Resource, Hangzhou 310007, China

${ }^{c}$ Qing Yang Institute for Industrial Minerals, You Hua, Qing Yang, Chi Zhou 242804, China

${ }^{d}$ Institut de Chimie des Milieux et Matériaux de Poitiers (IC2MP), UMR 7285 CNRS, Université de Poitiers, Poitiers Cedex 9, France

${ }^{e}$ Zhijiang College, Zhejiang University of Technology, Shaoxing 312030, China

Correspondence to: Prof.CH ZhouE-mail: clay@zjut.edu.cn; chc.zhou@aliyun.com 


\section{Abstract}

27

Modification of saponite (Sap) by surface engineering and intercalation chemistry introduces guest species into the structure of Sap and enhances the functionalities of the resultant Sap-based hybrids or composites. This review summarizes and evaluates latest scientific advances in the strategies for surface engineering, intercalation and hybridization of Sap, the insights into the relevant mechanisms, and the properties and applications of the resultant Sap-based materials. Studies have indicated that Sap can be inorganically modified by acid activation, inorganic cation exchange, pillaring, and adsorption. The methods of preparing organo-saponite (OSap) hybrids can be categorized as follows: 1) exchanging the inorganic cations in the interlayer space of Sap with organic cations; 2) covalent grafting of organic moieties or groups onto the surface of Sap; 3) intercalating polymer into the interlayer space of Sap by solution intercalation, and melt mixing or in situ polymerization. Organic-inorganic modified Sap can be made through the reactions between organic species and inorganic-modified Sap, or by the combination of inorganic species with organic-modified Sap. Modified Sap exhibits exceptional thermal stability, surface acidity, optical effects and adsorption. As such, the modified Sap can be used for optical materials, adsorbents, catalysts and clay/polymer nanocomposites $(\mathrm{CPN})$. Literature survey suggests that future studies should place emphasis on optimizing and scaling up the modification of Sap, probing the thermodynamics, kinetics and mechanisms of the modification of Sap, endowing Sap with novel functionalities, and accordingly advancing the practical applications of the resultant Sap-based materials.

Keywords: Saponite; Modification; Hybrid; Adsorbent; Catalyst; Saponite/polymer nanocomposite. 


\section{Introduction}

Saponite (Sap) is a 2:1 trioctahedral clay mineral and belongs to the smectite group. Typically, a layer of Sap is composed of two tetrahedral -O-Si-O- sheets sandwiching a central octahedral -O-Mg-Osheet (Fig. 1). A small amount of isomorphous substitution of $\mathrm{Si}^{4+}$ by $\mathrm{Al}^{3+}$ (and possibly other trivalent cations such as $\mathrm{Fe}^{3+}$ ) in the tetrahedral sheet causes the layer to be negatively charged. This charge is compensated by exchangeable interlayer cations including $\mathrm{Na}^{+}, \mathrm{NH}_{4}{ }^{+}, \mathrm{K}^{+}, \mathrm{Li}^{+}$, and $\mathrm{Mg}^{2+}\left(\mathrm{M}^{\mathrm{Z}}\right)$. In this context, the ideal structural formula of Sap can be described as $\mathrm{M}_{\mathrm{x} / \mathrm{z}}{ }^{\mathrm{z}}\left[\mathrm{Mg}_{6}\right]\left[\mathrm{Si}_{8-\mathrm{x}} \mathrm{Al}_{\mathrm{x}}\right] \mathrm{O}_{20}(\mathrm{OH})_{4} \cdot \mathrm{nH}_{2} \mathrm{O}$, where $\mathrm{M}^{\mathrm{zt}}$ represents the interlayer cations and $\mathrm{x}$ can range from approximately 0.4 to 1.2. The majority or even all the layer charge of Sap is located on the tetrahedral sheet and this has an important influence in the properties of Sap. Nevertheless, some studies have suggested that $\mathrm{Mg}^{2+}$ in the octahedral sheet can be substituted by trivalent cations such as $\mathrm{Al}^{3+}$. If $\mathrm{Mg}^{2+}$ cations are replaced by $\mathrm{Al}^{3+}$ cations at a ratio of $3 \mathrm{Mg}^{2+} / 2 \mathrm{Al}^{3+}$, the substitution in the octahedral sheet does create additional positive charges in the layer; If at a ratio of $1 \mathrm{Mg}^{2+} / 1 \mathrm{Al}^{3+}$, positive charges are created in the layer (Brigatti et al., 2013). The positive charges can partly compensate the negative charges of the tetrahedral sheet. $\mathrm{Mg}^{2+}$ in the octahedral sheet can also be substituted by other divalent cations $\left(\mathrm{Ni}^{2+}\right.$, $\mathrm{Co}^{2+} \cdot \mathrm{Fe}^{2}$, etc.) with no consequence on the layer charge.

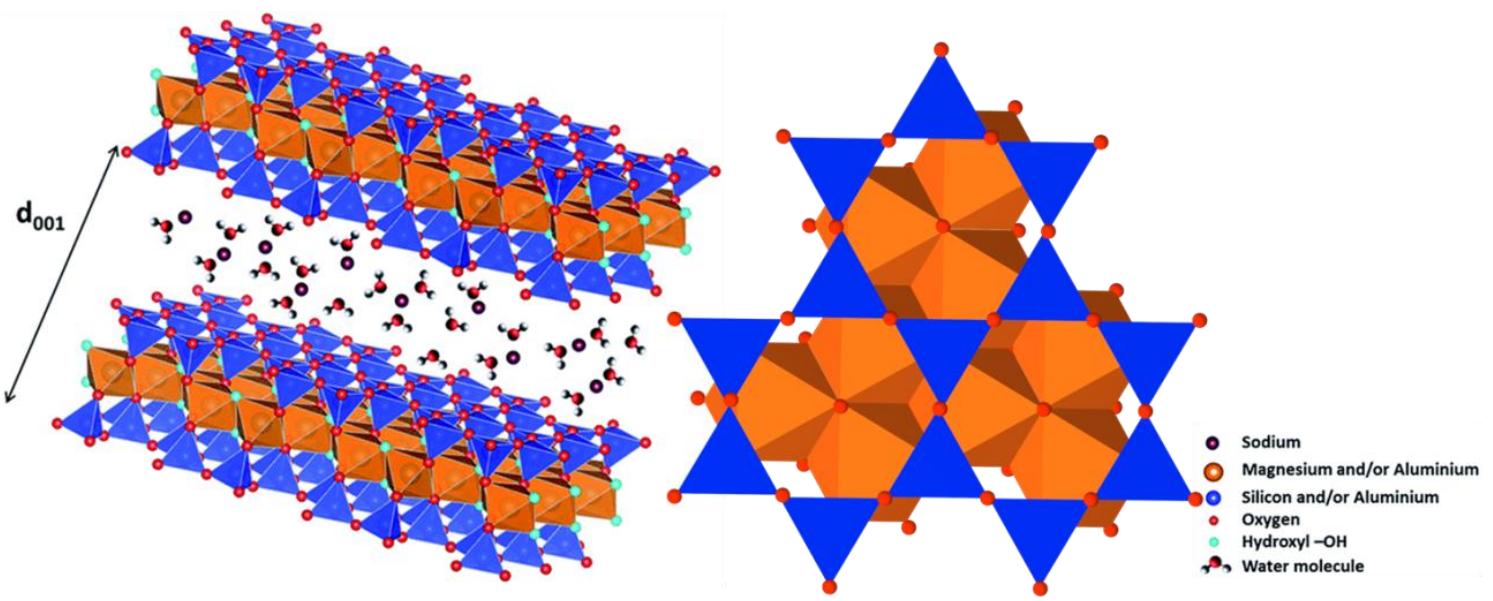

Fig. 1. (A) Structure of saponite, two $\mathrm{TO}_{4}\left(\mathrm{~T}=\mathrm{Si}^{4+}\right.$ and/or $\left.\mathrm{Al}^{3+}\right)$ tetrahedral sheets on each side of an octahedral sheet occupied by magnesium and/or aluminium cations, forming 2D layers (Figure is made by using the VESTA software) (Adapted and Reprinted from Lainé, et al., 2017, Copyright 2017, with permission from Royal Society of Chemistry under the terms of Creative Commons CC By License; Momma and Izumi, 2011). Each TOT layer has a thickness of roughly $9 \AA$. Compensating cations (here sodium) are present in interlayer space and are surrounded by water molecules. The $d_{001}$ value obtained from $X$-ray diffraction experiments enables determining the thickness of the interlayer space, and hence, the number of water layers in it (Lainé et al., 2017). (B) Top view of saponite structure (Figure is made by using the 3D Max software).

Saponite has a large specific surface area (SSA), surface acidity and cation exchange capacity (CEC). In addition, it is distinct from dioctahedral smectites such as montmorillonite (Mt) and nontronite. For example, Sap has a higher thermal stability than Mt (Casagrande et al., 2005; Vogels et 

al., 2005; Tao et al., 2016); the size of Sap particles ( $\sim 50 \mathrm{~nm})$ is generally smaller than that of $\mathrm{Mt}(\sim 300$ nm) (Ebina and Mizukami, 2007; Paul and Robeson, 2008). In addition, Sap is easier to delaminate and to be exfoliated into nanoplatelets, or even individual nanolayers in water (Takagi et al., 2013). However, naturally occurring Sap is scarce. Due to the presence of impurities in the Sap deposits in nature, laborious and time-consuming purification is required to obtain relatively pure Sap (Carrado et al., 2006). Moreover, the chemical composition of natural Sap can be extremely variable, depending on the geological genesis process (Utracki et al., 2007). This defects limits the use of natural Sap in catalysis (Gómez-Sanz et al., 2017), adsorption (Franco et al., 2016a) and optics (Tsukamoto et al., 2016b). Hence, Sap-like solids with well-controlled chemical composition are synthesized and such solid products are often called synthetic Sap. Generally, typical approach to the synthesis of Sap are hydrothermal synthesis (Suquet et al., 1977; Kloprogge, 1999; Zhang, et al., 2009; Jaber et al., 2013; Baldermann et al., 2014; Carniato et al., 2014; Zhang et al., 2017). The process can be modified to be microwave-assisted synthesis (Trujillano et al., 2010; Gebretsadik et al., 2014), and sol-gel synthesis (Garade et al., 2011; Garciano et al., 2014).

The synthesis of Sap is relatively mature, at least on a laboratory scale. However, either natural Sap or synthetic Sap is rarely used directly. Under many circumstances the Sap needs modification, including surface engineering, intercalation and hybridization of Sap. Taking advantage of the swellability of Sap (Ferrage et al., 2010; Dazas et al., 2015; Ferrage, 2016), researchers can introduce functional guest molecules into the structure of Sap and thus tune porosity, acidity and other physical and chemical properties. Many types of Sap-based hybrids or composites have been successfully prepared by the intercalation of bulky organic (Kurokawa et al., 2014; Marcal et al., 2015; Sas et al., 2017) and inorganic (Franco et al., 2016b; Miyagawa et al., 2017) cationic species, neutral polar molecules (Marcal et al., 2015) and polymers (Mishchenko et al., 2016; Eguchi et al., 2017) into the interlayer space of Sap. Covalent grafting of a moiety of organic molecules onto the surface of Sap proves feasible. Accordingly, the resultant Sap-based materials have been examined for a wide range of applications. Increasing studies show that such materials can be used as adsorbents (Marcal et al., 2015; Sato et al., 2016), catalysts and catalyst supports (Carniato et al., 2014; Fatimah et al., 2016). They can also be used as a functional additive in clay/polymer nanocomposites (CPN) (Wu et al., 2014; Wang et al., 2015) (Fig. 2). Strikingly, Sap has been used as a support for the immobilization of luminescent 


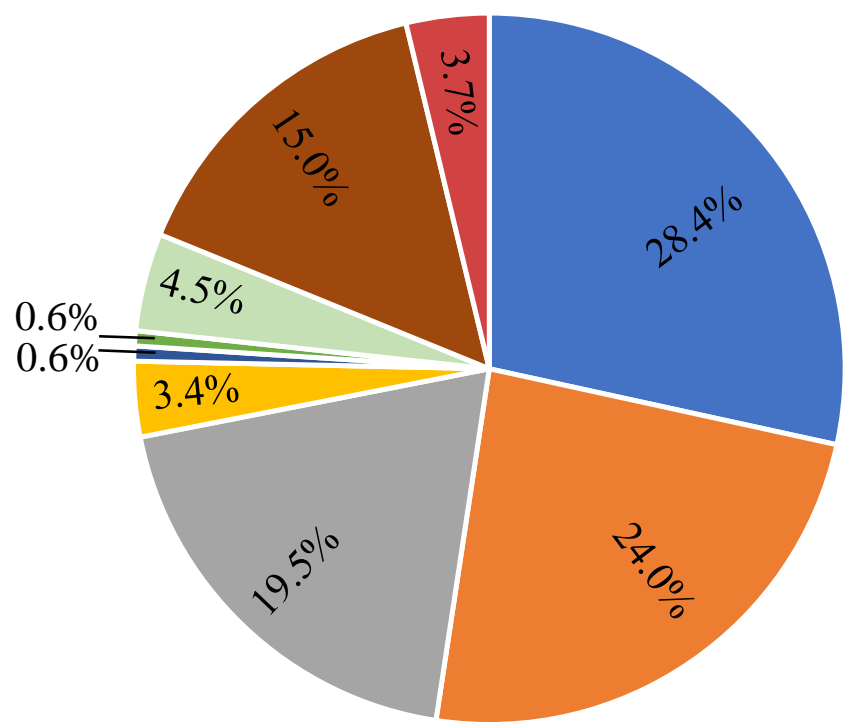

- Polymer nanocomposite

- Catalyst

- Adsorbent

- Wastewater treatment

- Caffeine removal

- Agriculture

Radioactive

- Optical material

- Others

(B)

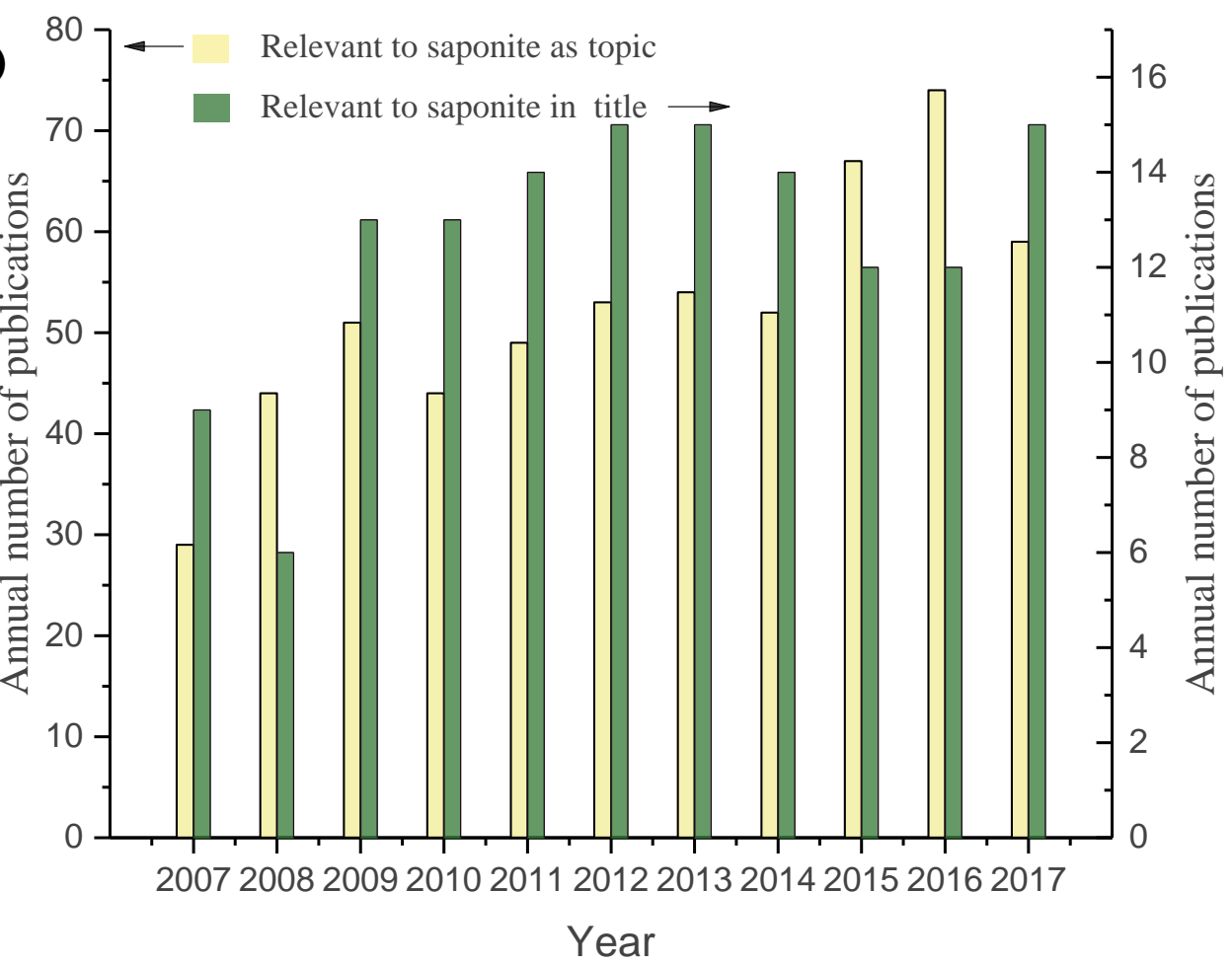

Fig.2 (A) Application category distribution of saponite (by percentage) according to peer-reviewed scientific papers published (from 2007 to end of 2017). (Data from Web of SciencetCore Collection. Search terms: saponite, polymer 
nanocomposite, catalyst, adsorbent, wastewater treatment, caffeine removal, agriculture, radioactive, optical material) (B) Annual number of peer-reviewed papers published (from 2007 to 2017) relevant to the topics of saponite and the title contain saponite. (Data from Web of SciencetCore Collection. Search terms: saponite).

\section{Inorganic modification and hybridization of saponite}

The inorganic modification of Sap is mainly achieved by the exchange of cations $\mathrm{M}^{\mathrm{z+}}$ in the interlayer space of Sap with external inorganic cations or the generation of oxides in the form of pillars in the interlayer space of Sap. The frequently-used methods include acid activation $\left(\mathrm{M}^{\mathrm{z}+}\right.$ exchanges with $\mathrm{H}^{+}$), inorganic cation exchange (exchange with inorganic metal cations), pillaring $\left(\mathrm{M}^{\mathrm{Z}}\right.$ first exchanged with inorganic metal hydroxycations, followed usually by calcination to form oxide pillars), and the hybridization of metal nanoparticles with Sap to form nanocomposite. After such inorganic modifications, the interlayer spacing, the thermal stability and the surface acidity of Sap are usually increased. Thus the resultant Sap-based materials are commonly used as catalysts and adsorbents.

\subsection{Acid activation and inorganic cation exchange}

Acid activation refers to the process treating Sap with mineral acids such as sulphuric acid or hydrochloric acid. The final texture and structure of the treated Sap is dependent upon the concentration of the acid used in the process. The product can be $\mathrm{H}^{+}$- Sap because merely $\mathrm{M}^{\mathrm{z}+}$ cations in the interlayer space of Sap are exchanged by $\mathrm{H}^{+}$. It can also be smaller particulate $\mathrm{H}^{+}$-Sap if part of Sap particles has been dissolved or damaged by the acid. It is worth noting that the dissolution of Sap is much easier than that of Mt. Hence, the final product can even be an amorphous silica (Komadel and Madejova, 2013). In the former two cases, the $\mathrm{H}^{+}$- Sap usually exhibits increased surface acidity, SSA and pore volume (Komadel and Madejova, 2013; Franco et al., 2016b). A recent study shows that the microwave irradiation as heating in the acid activation of Sap can remarkably reduce the time for acid activation (Franco et al., 2016b). Similar to acid-activated Mt (also known as bleaching earth), such acid-activated Sap can be used as adsorbents (Ugochukwu et al., 2014a; Ugochukwu and Fialips, 2017a) and as catalysts (De Stefanis et al., 2013) or catalyst supports (Gebretsadik et al., 2016, 2017b).

The inherent nature of acid activation of Sap is a cation exchange reaction. As such, the exchangeable cations $\mathrm{M}^{\mathrm{z+}}$ in the interlayer space of Sap are replaced by $\mathrm{H}^{+}$ions. Nevertheless, under many circumstances, the dissolution of part of the octahedral and tetrahedral sheets often occurs 
simultaneously (Kaviratna and Pinnavaia, 1994; Komadel and Madejová, 2013). The dissolution of the whole layer is also possible if the acid is strong enough. As a result, due to the attack by the proton $\mathrm{H}^{+}$, the structural cations are released from the layers, leading the breakage of the layers (Kaviratna and Pinnavaia, 1994; Komadel and Madejová, 2013). Such attack prefers to be at the edge of the layer which is the broken-bond plane, but it can also take place on the oxygen plane.

When Sap is treated by mild acid and harsh conditions usually caused by the acid and temperature, the morphology, structure, and texture of the resultant acid-treated Sap appears different (Bisio et al., 2008; Guidotti et al., 2009). When Sap is treated under mild conditions, usually the amount of Brønsted acid sites increases without little alteration of the structure of Sap. In contrast, when Sap is treated under harsh conditions, the cation exchange reaction is also accompanied by progressive dealumination of the framework (layer) of Sap. Accordingly, a significant amount of porous amorphous silica can be produced. Though microporosity and SSA are largely increased, the number of Brønsted acid sites significantly decreases.

In addition to acid activation, the original cations $\mathrm{M}^{\mathrm{z+}}$ in the interlayer space of Sap can also be exchanged with other inorganic cations, such as $\mathrm{Li}^{+}, \mathrm{Cu}^{2+}, \mathrm{Ni}^{+}$(Vicente et al., 2011), $\mathrm{Zn}^{2+}$ (Intachai et al., 2017), and $\mathrm{Fe}^{3+}$ (Franco et al., 2016a). In particular, $\mathrm{Cu}^{2+}, \mathrm{Ni}^{+}$and $\mathrm{Fe}^{3+}$ can be converted into zero-valent metal nanoparticles by appropriate reduction reaction. In this context, two-dimensional Sap acts as a nanoreactor with limited space for generating metal nanoparticles and such metal nanoparticles are -free of organic protectants (Miyagawa et al., 2017).

\subsection{Pillaring, supporting and hybridization}

A typical pillaring procedure of Sap involves the introduction of pre-prepared bulky inorganic metal polyhydroxycations or polyoxocation into the interlayer space of Sap by a cation exchange reaction or the electrostatic attraction, following by calcination, which usually cause dehydration, dehydroxylation and oxidation of the intercalated species (Fig. 3A) Hence, the polyoxocations are converted to metal oxide clusters called pillars commonly (Gil et al., 2000). If the solid is calcined under a flow of $\mathrm{H}_{2}$, a reduction reaction occurs. Namely, the layered structure of Sap is pillared by the metal oxide clusters. The pillars stably expand the 2:1 layers of Sap, prevent its collapse, expose their internal surface and make the pillared Sap with micro- to mesoporosity (Ding et al., 2001; Vicente et al., 
2013). In addition, the pillars bring additional acid sites or redox sites and thus provide catalytic active species for specific catalysis and adsorption (Table 1). Upon the pillaring procedures, the precursors and the chemical compositions of pillars, the interlayer spacing and the porosity of the pillared Sap vary.

(A)

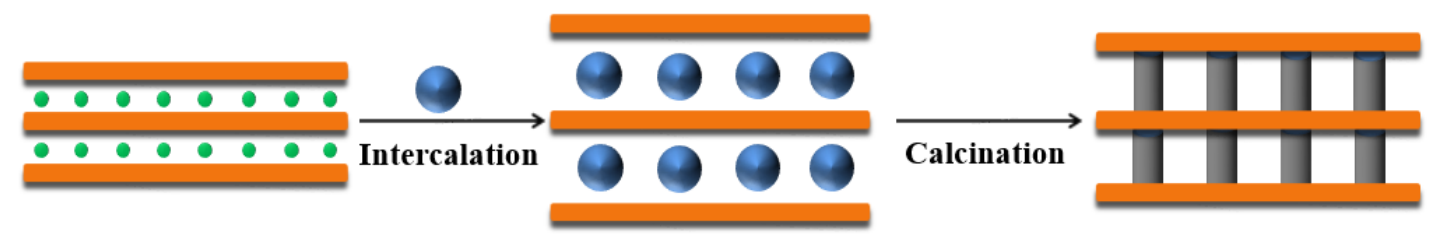

Saponite

Polyoxocation-intercalated

Pillared

- Exchangable cation

Polyoxocation

Pillar

(B)

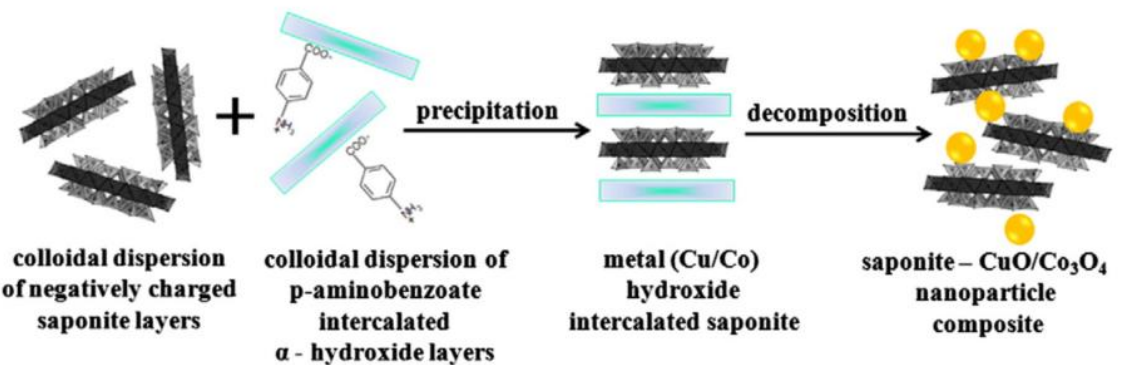

Fig. 3 Schematic representation of (A) A typical pillaring process. (B) A process to prepare metal oxide nanoparticle /saponite nanocomposite (Reprinted from Nityashree et al., 2014, Copyright 2014, with permission from Elsevier). The steps mainly include the synthesis of metal hydroxide intercalated saponite and their decomposition to metal oxide nanoparticle /saponite-nanocomposite. Layered $\alpha$-hydroxide and hydroxysalt [or basic salt] are obtained by intercalating p-aminobenzoic acid (PABA) into the interlayer space.

Table 1. Basal spacing $\left(d_{001}\right)$, pore volume, surface area and applications of metal pillared saponite.

\begin{tabular}{lcccccc}
\hline $\begin{array}{c}\text { Pillaring } \\
\text { agent }\end{array}$ & Amount & $\begin{array}{c}\mathbf{d}_{001}{ }^{*} \\
(\AA)\end{array}$ & $\begin{array}{c}\mathrm{V}_{\mathbf{p}}^{*} \\
\left(\mathrm{~cm}^{3} / \mathrm{g}\right)\end{array}$ & $\begin{array}{c}\mathrm{S}_{\mathrm{BET}}{ }^{*} \\
\left(\mathrm{~m}^{2} / \mathrm{g}\right)\end{array}$ & Applications & Ref. \\
\hline
\end{tabular}




\begin{tabular}{|c|c|c|c|c|c|c|}
\hline $\mathrm{Al}_{13}$ & $5 \mathrm{mmol} / \mathrm{g}$ & 17.8 & 0.188 & 177 & & \\
\hline Cs- $\mathrm{Al}_{13}$ & $0.25 \mathrm{wt} \%{ }^{\mathrm{a})}$ & 18.0 & 0.167 & 95 & $\begin{array}{l}\text { Catalyst for the synthesis of } \\
\text { N-alkyl pyrazoles. }\end{array}$ & $\begin{array}{l}\text { Velasco et al. } \\
\qquad \text { (2011) }\end{array}$ \\
\hline Cs- $\mathrm{Al}_{13}$ & $1.25 \mathrm{wt} \%$ & & 0.156 & 111 & & \\
\hline $\mathrm{Al}_{13}$ & $5 \mathrm{mmol} / \mathrm{g}$ & 18.0 & - & 274 & $\begin{array}{c}\text { Catalyst for acetalation of } \\
\text { pentaerithritol }\end{array}$ & $\begin{array}{l}\text { Kannan et al. } \\
\text { (2011) }\end{array}$ \\
\hline $\mathrm{Al}$ & - & 17.6 & 0.120 & 134 & & \\
\hline $\mathrm{Fe} / \mathrm{Al}$ & $\begin{array}{c}\mathrm{Al}: 12 \\
\mathrm{mmol} / \mathrm{g} \\
\mathrm{Fe}: 1 \\
\mathrm{mmol} / \mathrm{g}\end{array}$ & 18.2 & 0.130 & 162 & $\begin{array}{c}\text { Catalyst for the cracking of } \\
\text { polyethylene }\end{array}$ & $\begin{array}{l}\text { De Stefanis et } \\
\text { al. (2013) }\end{array}$ \\
\hline $\begin{array}{c}\mathrm{Zr} \\
\mathrm{Ni} / \mathrm{Zr}\end{array}$ & $1 \mathrm{wt} \%$ & 14.3 & $\begin{array}{l}0.053 \\
0.042\end{array}$ & $\begin{array}{l}233 \\
199\end{array}$ & $\begin{array}{c}\text { Catalyst for the isopulegol } \\
\text { hydrogenation }\end{array}$ & $\begin{array}{l}\text { Fatimah et al. } \\
\qquad(2015)\end{array}$ \\
\hline $\mathrm{Al}$ & $10 \mathrm{mmol} / \mathrm{g}$ & $\begin{array}{c}17.0 \\
16.6^{\mathrm{b})}\end{array}$ & $0.042^{1}$ & ${ }^{-}$ & \multirow{2}{*}{$\begin{array}{c}\text { Photocatalytic phenol } \\
\text { photo-oxidation } \\
\text { in aqueous solution }\end{array}$} & Fatimah and \\
\hline $\mathrm{Al}-\mathrm{Ti}$ & $1.2 \mathrm{wt} \%$ & - & $\begin{array}{c}0.019 \\
0.019^{1}\end{array}$ & $\begin{array}{c}132 \\
276^{1}\end{array}$ & & Wijaya (2015) \\
\hline $\mathrm{Fe}$ & $20 \mathrm{mmol} / \mathrm{g}$ & 12.8 & 0.160 & 127 & $\begin{array}{l}\text { Adsorption of heavy metal } \\
\text { cations from water }\end{array}$ & $\begin{array}{l}\text { Franco et al. } \\
\qquad(2016 a)\end{array}$ \\
\hline \multirow[b]{2}{*}{ Magnetite } & $2 \mathrm{wt} \%$ & & 0.1441 & 53 & \multirow[b]{2}{*}{$\begin{array}{c}\text { Adsorption of dyes from } \\
\text { aqueous solution }\end{array}$} & \multirow[b]{2}{*}{$\begin{array}{c}\text { Makarchuk et } \\
\text { al. (2016) }\end{array}$} \\
\hline & $\begin{array}{l}4 \mathrm{wt} \% \\
7 \mathrm{wt} \% \\
10 \mathrm{wt} \%\end{array}$ & - & $\begin{array}{l}0.1455 \\
0.1464 \\
0.3058\end{array}$ & $\begin{array}{l}56 \\
53 \\
69\end{array}$ & & \\
\hline $\begin{array}{c}\mathrm{Zr} \\
\mathrm{S}-\mathrm{Zr}\end{array}$ & $5 \mathrm{wt} \%$ & 13.4 & 0.0054 & $\begin{array}{l}177 \\
190\end{array}$ & $\begin{array}{l}\text { Catalyst for the conversion of } \\
\text { citronellal into menthol }\end{array}$ & $\begin{array}{l}\text { Fatimah et al. } \\
\qquad(2016)\end{array}$ \\
\hline
\end{tabular}

213 a) Saponite pillared with $\mathrm{Al}$ and then the pillared solid doped with Cs. b) Samples prepared by using microwave irradiation as calcination procedure instead of conventional calcination method. $\mathrm{S}_{\mathrm{BET}}$ : specific surface area calculated according to the BET equation; $\mathrm{V}_{\mathrm{p}}=$ total pore volume; $\mathrm{S}-\mathrm{Zr}$ : sulphated zirconium pillared saponite.

As the precursors of the pillars, also called pillaring agents, can be metallic cations, metallic oxide 219 sol, polyhydroxycations or polyoxocations (Table 1). $\left[\mathrm{Al}_{13} \mathrm{O}_{4}(\mathrm{OH})_{24}\left(\mathrm{H}_{2} \mathrm{O}\right)_{12}\right]^{7+}$ usually abbreviated as $220 \mathrm{Al}_{13}$ is the most widely studied (Trujillano et al., 2009; Kannan et al., 2011; Velasco et al. , 2011). 221 Accordingly, the Al-pillared saponite is well-documented. This is mainly because the preparation of $\mathrm{Al}_{13}$ is very mature and its structure is better understood than that of other cations. In addition, $\mathrm{Al}_{2} \mathrm{O}_{3}$ 
pillars is thought to possess solid acidity. Particularly, thermal resistance of Al-pillared Sap is higher than that of Al-pillared Mt (Chevalier et al., 1994; Lambert et al., 1994; Bergaoui et al., 1995a,b). Pillars made from polycations which formed by the hydrolysis of $\mathrm{Zr}^{4+}, \mathrm{Ti}^{4+}, \mathrm{Fe}^{3+}$, or $\mathrm{Ga}^{3+}$ (Malla and Komarneni, 1993; Vicente et al., 2008; Fatimah et al., 2015; Fatimah and Wijaya, 2015; Franco et al., 2016a; Makarchuk et al., 2016; Gebretsadik et al., 2017b) has also been reported. It is worth mentioned that $\mathrm{Ni}^{2+}$ cation does not form polycations upon hydrolysis. In general, the basal spacing and the pore size of the resultant pillared Sap are inherently decided by the size of the oligomers and accordingly the products after calcination (Vicente et al., 2008; Franco et al., 2016a). In the two-dimensional network of pillared Sap, interlayer spacing is controlled by the height of the pillars, whereas both the distance between the pillars and the height of the pillars known as inter-pillar distance, determines the pore size. The inter-pillar distance also reflects the density of pillars in the interlayer space of Sap. Of great challenge is the interactions between guest pillars and the layers of the Sap. For Al-pillared Sap, the -O-Al-O- on the $\mathrm{Al}_{2} \mathrm{O}_{3}$ pillars could form covalent bonds with - $\mathrm{Al}-\mathrm{O}$ and -Si-O on the layer of Sap. However, for many other elements with $4 \mathrm{f} / 5 \mathrm{f}$ orbitals, the interactions remain unclear. Possibly theoretical modeling can be conducive to getting more insights into this issue (Bian et al., 2015; Dong et al., 2016). Besides, it has not yet to find an effective way to measure the size and charge of each individual pillar accurately.

Though the chemical composition and structure of the metallic cation or its polycation used in the pillaring process play a pivotal role in the characteristics and properties of the pillars in the pillared Sap, other important factors such as the concentration of the pillaring agent (Khumchoo et al., 2016; Makarchuk et al., 2016), the drying method and the calcination temperature (Vicente et al., 2008) have

significant effect on the pillars. For instance, recently, Fatimah and Wijaya (2015) found that during the calcination procedure, when microwave irradiation for $15 \mathrm{~min}$ was used, the Al-pillared Sap with a higher SSA was obtained, compared with the Al-pillared Sap by conventional slow heating for $4 \mathrm{~h}$. Inherently, under the two different calcination methods, the conversion of polycations would be different. As conventionally to prepare pillared Sap need a long procedure, rapid microwave irradiation to produce nanocomposite. To this end, there are such ways as impregnation and deposition. Also the 
oxide on a cetyltrimethylammonium cation $\left(\mathrm{CTA}^{+}\right)$-intercalated Sap (Khumchoo et al.,2016) while in the case of Ni, this metal is supported on Sap (Gebretsadik et al.,2017b). Notably, Sap easily delaminates or can be exfoliated in water. By spontaneous flocculation of delaminated Sap, the delaminated or exfoliated Sap can then be used to host other layered nanomaterials (e.g. $\mathrm{Co}, \mathrm{Cu}$ hydroxide) to form composites (Nityashree et al., 2014). Upon calcination, the metal hydroxide therein decomposes to form metal oxide nanoparticle/Sap nanocomposite in which the nanoparticles get uniformly distributed in Sap matrix (Fig. 3B). The particle size of the metal oxide nanoparticles formed in the nanocomposite could be altered by varying factors such as the temperature, atmosphere and duration of decomposition. If the nanoparticles are chosen to be nanosized magnetite, then a magnetic nanocomposite can be achieved (Makarchuk et al., 2016).

\section{Organic modification of saponite}

Positively charged organic cations can be intercalated into the interlayer space of Sap by cation exchange or adsorption to produce OSap (Zhen and Wang, 2016; Tominaga et al., 2017). The inorganic cations in the interlayer space of Sap, that compensate the negatively charged layer, can be exchanged with positively charged organic cations. Such cations can be formed from surfactants, dye or organometallic complexes in water (Kurokawa et al., 2014; Seki et al., 2015; Sas et al., 2017). The organic cations are not only intercalated in the interlayer space of Sap, but also adsorbed on the surface of Sap to form an electric double layer. Such organic modification of Sap is easily achieved. Studies have demonstrated that during the synthesis process of Sap, OSap can be synthesized in a one-pot way by the direct adding organic cations into the inorganic gel for synthesizing Sap (Bisio et al., 2011; Kurokawa et al., 2014). The surface of Sap is usually hydrophilic and the inorganic cations in the interlayer space tend to be hydrated (Ferrage, 2016). When such places are occupied by organic species after organic modification, the surface is then covered by organic carbon chains or groups, thus the hydrophilic Sap are changed into hydrophobic OSap. Accordingly, the polarity is altered (de Paiva et al., 2008). Besides, a wide range of organic cations, groups or molecules can be used and can perform a variety of functions such as in optical properties (Wu et al., 2015), adsorption (Seki et al., 2010, 2015) and catalysis (Goto et al., 2016). In addition, the inorganic layers of Sap play an active role in stabilizing and protecting the intercalated organic species. Typically, their thermal stability or 


\subsection{Organic cations}

By taking advantage of cation exchangeability of Sap, organic cations can be incorporated into the interlayer space of Sap by a cation exchange reaction. Consequently, organic cations replace the original inorganic cation in the interlayer space of Sap to compensate the negative electric charge in the layer of Sap. Such organic cations are commonly moieties of cationic surfactants such as cetyltrimethylammonium (CTA), benzylammonium (BA), and didecyldimethylammonium (DDDMA) cations. In particular, cationic surfactants have been successfully used as organic modifiers of Mt to produce organo- Mt in industry (Lagaly and Weiss, 1969; Lagaly, 1981, 1986; Yu et al., 2014). In addition, over the last decade, quaternary fulvic acid (QFA), and aminopropyl isobutyl titanosilsesquioxane (Ti- $\mathrm{NH}_{3} \mathrm{POSS}$ ) have also been used to modify Sap (Table 2).

After organic modification, the surface of the Sap becomes hydrophobic from hydrophilic (Ugochukwu et al., 2014b; Ugochukwu and Fialips, 2017b). Depending on the layer charge density (LCD) of Sap, and the chain length or the stereoscopic structure and geometric size of organic cations, the extent to which the inorganic cations are replaced by the organic cations, the organic moieties appear to have several types of arrangements in the interlayer space of Sap. In the interlayer space of Sap, the organic cations may lie flat as a monolayer (Okada et al., 2014) or bilayer (Marcal et al., 2015) pseudo-trilayers or multilayers (Yu et al., 2014). Clearly, the arrangements of organic cations, along with the length of their carbon chains, decide the degree of expansion of the Sap. For example, for BA-intercalated Sap, when $\mathrm{BA}^{+}$cations occur in the form of a monomolecular layer, the cations should be aligned parallel to the oxgen plane of the Sap layer. As a result, the interlayer spacing of BA-Sap can be increased a little by a few Angstroms from the basal spacing $1.26 \mathrm{~nm}$ of original Sap (Okada et al., 2014). By contrast, for CTA-intercalated Sap, when an arrangement of bilayer $\mathrm{CTA}^{+}$ions is achieved, the interlayer spacing of Sap increases remarkably by several Angstroms to a few nanometers (Marcal et al., 2015). In this case, the ammonium groups occur like being tethered to the surface Sap layer, and the alkyl chains lay almost vertical to the layers. Moreover, the intercalated organic cations may undergo a conformational change when the thickness of the intercalated molecule is larger than the interlayer spacing of Sap. This conformational change depends on the extent of loadings of organic species and the layer charge density of Sap (Tominaga et al., 2017). 
Table 2. Characteristics of some organic modified saponite (Sap).

\begin{tabular}{|c|c|c|c|c|c|}
\hline Modifier & $\begin{array}{c}\text { Amounts } \\
\text { (modifier/Sap) }\end{array}$ & $\begin{array}{c}\text { Basal spacing } \\
\quad(\mathbf{n m})\end{array}$ & $\begin{array}{c}\mathbf{S}_{\mathrm{BET}}^{\#, *} \\
\left(\mathbf{m}^{2} / \mathbf{g}\right)\end{array}$ & $\begin{array}{c}\text { Interlayer* } \\
\text { space }(\Delta d) \\
(\mathbf{n m})\end{array}$ & Ref. \\
\hline Ti-NH ${ }_{3}$ POSS & - & - & - & 2.60 & $\begin{array}{l}\text { Carniato et al. } \\
(2009,2011)\end{array}$ \\
\hline $\mathrm{CONH}$ & $110 \% \mathrm{CEC}$ & 1.51 & 144 & 0.55 & $\begin{array}{l}\text { Seki et al. (2010, } \\
\text { 2015) }\end{array}$ \\
\hline CTAB & $200 \%$ CEC & $\begin{array}{l}1.43^{\mathrm{a})} \\
1.35^{\mathrm{b})}\end{array}$ & - & - & Bisio et al. (2011) \\
\hline $\begin{array}{c}\mathrm{BA} \\
\mathrm{CONH}\end{array}$ & $\begin{array}{c}50,100 \% \text { CEC } \\
200 \% \text { CEC }\end{array}$ & $\begin{array}{c}1.31,1.30 \\
1.51\end{array}$ & - & $\begin{array}{c}0.35,0.34 \\
-\end{array}$ & Okada et al. (2014) \\
\hline Arquad 2HT-75 & $500 \% \mathrm{CEC}$ & 3.60 & & & \\
\hline Octadecylamine & $50 \%$ CEC & 1.42 & - & & Albeniz et al. (2014) \\
\hline OTAB & $200 \%$ CEC & 1.92 & & & \\
\hline DDDMA & $35 \% \mathrm{CEC}$ & 1.40 & $\begin{array}{c}\text { 330(EGME) } \\
\text { 우 }\end{array}$ & - & $\begin{array}{l}\text { Ugochukwu et al. } \\
\text { (2014b, 2017b) }\end{array}$ \\
\hline CTAB & - & 1.84 & 0.1 & 0.88 & Marçal et al. (2015) \\
\hline QFA & $50 \mathrm{wt} \%$ & 1.57 & - & - & $\begin{array}{l}\text { Zhen and Wang, } \\
\text { (2016) }\end{array}$ \\
\hline $\mathrm{BP}$ & $10-27 \%$ CEC & - & - & $0.51-0.55$ & $\begin{array}{l}\text { Tominaga et al. } \\
\text { (2017) }\end{array}$ \\
\hline
\end{tabular}

\# The specific surface area (SSA) of the samples was determined by BET equation. ㅇ The SSA of the samples was determined by the EGME (Ethylene glycol monoethyl ether) method (Carter et al., 1965) * For clarity, consistency, and easy comparison, some original data have been rounded off.

a) One-pot synthesized CTA-Sap. ${ }^{\text {b) }}$ Post synthesized CTA-Sap.

Ti- $\mathrm{NH}_{3}$ POSS: aminopropyl isobutyl titanosilsesquioxane; $\mathrm{CONH}$ : neostigmine; CTAB: cetyltrimethylammonium bromide; BA: benzylammonium; OTAB: trimethyloctadecylammonium bromide; DDDMA: didecyldimethylammonium; QFA: quaternary fulvic acid; BP: biphenyl derivative.

A one-pot strategy for producing OSap has been developed as an alternative to the post-modification method of Sap (Roelofs and Berben, 2006; Bisio et al., 2011). This new method can intercalate organic cations into the interlayer space of Sap by the direct introduction of organic cations in the gel used for synthesizing Sap during the process (Fig. 4). By this methodology the procedure of producing OSap is significantly simplified and no longer time-consuming. Moreover, a low amount of surfactant is needed in such a method that thereby lowers the costs of producing OSap. Besides, the distribution of surfactant molecules could be more homogeneous in the OSap (Bisio et al., 2011) 


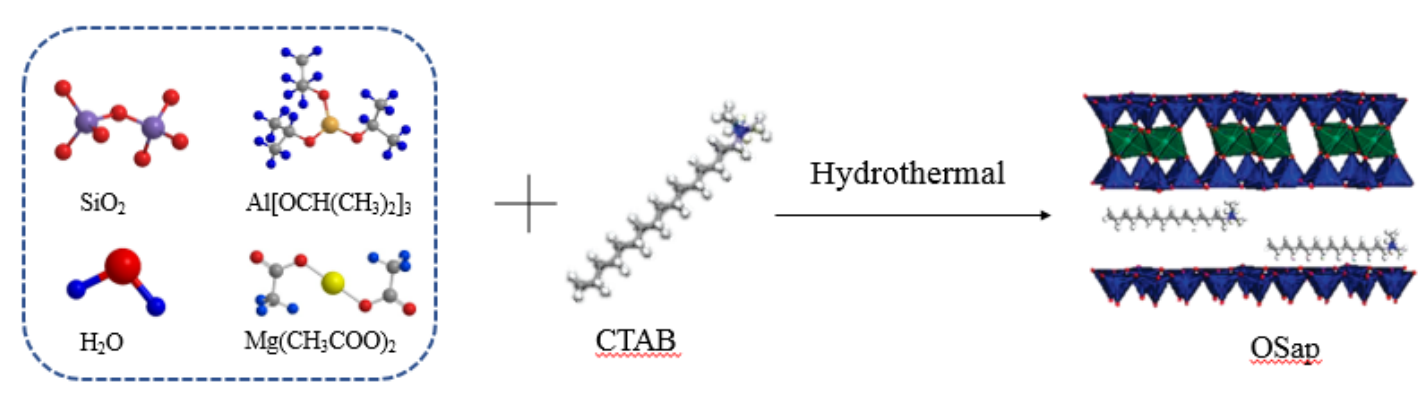

328

Fig. 4 Schematic drawing showing one-pot synthesis of organo-saponite (OSap) (Bisio et al., 2011). CTAB: cetyltrimethylammonium bromide.

\subsection{Dye molecule}

Compared with Mt, Sap is more easy delaminated completely in water to form a transparent dispersion. Such optical transparency, together with high absorption capacity of Sap, make it a very good two-dimensional inorganic host for many organic dye molecules with optical functions (Tsukamoto et al., 2016b), in particular fluorescence. The interlayer space and the layer charge can provide a static confinement to the fluorescent dyes and is conducive to better distribution and assembly of the dye molecules, thereby preventing fluorescence from quenching. A variety of dye molecules, including porphyrin dyes (Takagi et al., 2013; Konno et al., 2014), cyanine dyes (Takagi et al., 2013; Czímerová et al., 2017; Matejdes et al., 2017), acetylene derivatives (Suzuki et al., 2014), methylene blue (MB) (Donauerová et al., 2015), triphenylbenzene derivatives (Tokieda et al., 2017), biphenyl derivative (BP) (Tominaga et al., 2017), laser dyes rhodamine 6G (R6G), oxazine 4 (Ox4) (Belušáková et al., 2017), and anthocyanin (Ogawa et al., 2017) have been successfully introduced onto the surface or into the interlayer space of Sap. The driving forces involve cation exchange reactions, electrostatic attraction, hydrophobic interaction, van der Waals force, physical adsorption and chemisorption between dye and Sap.

Organic dye cations generally tend to aggregate on the surface of Sap, due largely to the hydrophobic interaction and van der Waals force between organic species (Konno et al., 2014; Donauerová et al., 2015; Matejdes et al., 2017; Sas et al., 2017; Tokieda et al., 2017). The aggregates are categorized into two types: H-aggregates and J-aggregates. The former more frequently occurs and is based on a sandwich-type intermolecular association and absorb the light of higher energy; the latter appears less frequent and are formed by a head-to-tail intermolecular association. The types of the 
aggregates are related to the amount of adsorbed dye cations. At higher ratio of dye/Sap, a large amount of $\mathrm{H}$-aggregates tends to form whereas at the lower ratio of dye/Sap, J-aggregates are preferentially formed (Boháč et al., 2016). The amount of the J-aggregates also increased with the aging of hybrid colloids and is influenced by the solvents (Czímerová et al., 2017). In reverse, segregation of dye cations on the surface of Sap often occurs (Konno et al., 2014). Segregation behavior depends primarily on the chemical structure of the dye cations. Such aggregation drastically reduces the efficiency of the intermolecular photochemical reactions because the functional dye cations are separated from each other in the interlayer space of Sap or on the surface of Sap.

The structure of dye assembly on Sap can be effectively controlled by the electrostatic host-guest interaction (Takagi et al., 2013). It includes the intermolecular distance, the molecular orientation, the segregation, aggregation and integration, and the strength of the immobilization. In this context, a size-matching effect have been proposed. In addition, the arrangement of organic fluorescent dyes can be also affected by the layer charge density of Sap (Wu et al., 2015). Hence, it can be tuned by changing the layer charge of Sap. According to a recent study by molecular dynamic simulation, (Wu et al., 2015) as to bis-N-methylacridinium (BNMA)-intercalated Sap, when the layer charge density increased, the electrostatic attraction between the layer of Sap and BNMA became stronger, and BNMA in the interlayer space of Sap tended to arrange in a monolayer parallel to the layer. The parallel orientation suppressed remarkably the molecular aggregation, preserving the photoactivity of dye molecules.

\subsection{Organometallic complex}

Some organometallic complexes can be introduced into the interlayer space of Sap and interact with the anionic layers of Sap. The confinement of organometallic complexes in the interlayer space of Sap can regulate the molecular structure and the relevant arrangements, and increase the stability of the complexes (Pimchan et al., 2014). Much importantly, the intercalation of organometallic complexes into the interlayer space of Sap brings additional functions caused by the organometallic complexes. In other words, the organometallic complex-Sap hybrids can act as catalysts (Pimchan et al., 2014; Kurokawa et al., 2014; Goto and Ogawa, 2016), catalyst support (Goto and Ogawa, 2015) or optical materials (Sato et al., 2014a; Hosokawa and Mochida, 2015; Tamura et al., 2015; Eguchi et al., 2017).

Up to now, many organometallic complexes, including bis(8-hydroxyquinoline)zinc(II) complex ( $\left.\mathrm{Znq}_{2}\right)$ (Pimchan et al., 2014), iridium(III) complexes (Sato et al., 2014a; Tamura et al., 2015), nickel(II) 
complexes with diketonato and diamine ligands (Hosokawa and Mochida, 2015), tris(2,20-bipyridine) ruthenium(II) complex $\quad\left(\left[\mathrm{Ru}(\mathrm{bpy})_{3}\right]^{2+}\right) \quad($ Goto and Ogawa, 2016), and iron(II)-based metallo-supramolecular complex polymer (polyFe) (Eguchi et al., 2017) have been used to modify Sap to produce organometallic complex-Sap hybrids. Typically, the intercalation of an organometallic complex in the interlayer space of Sap is achieved by exchanging the inorganic cations in the interlayer space of Sap with cationic organometallic complexes. Recently, a new process to produce organometallic complexes -Sap hybrids have been developed by Kurokawa et al. (2014) (Fig. 5). In this process, transition-metal complex/Sap hybrids have been in situ synthesized successfully, instead the complexes should be pre-synthesized usually. The $\mathrm{Fe}^{3+}$ - and $\mathrm{Ni}^{2+}$-exchanged Sap acted as an acid catalyst and promoted ligand formation from an aniline derivative and a ketone derivative. The formed ligand then simultaneously coordinated to the metal ions located in the interlayer space of Sap to form bis(imino)pyridineiron(III), $\alpha$-diiminenickel(II), and iminopyridinenickel(II) complexes, respectively. Such methodology tactically combines catalysis, ligand synthesis, complex synthesis and immobilization together in a one-pot process and can be regarded as a more efficient and cleaner approach to producing organometallic complex -Sap hybrids.
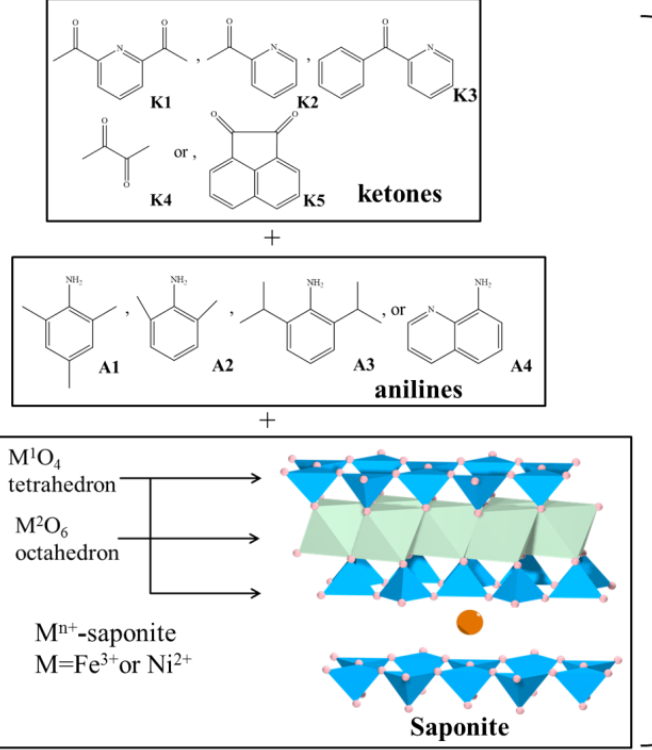

Fig. 5 One-pot preparation of transition-metal complex/saponite hybrid (Adapted and reprinted from Kurokawa et al., 2014, Copyright 2014, with permission from Elsevier). 


\subsection{Grafting organic moiety and silylation}

Beside cations, neutral organic molecules can also be intercalated into the interlayer space of Sap. Generally, cation exchange method cannot be used to introduce neutral organic molecules into Sap. Instead, in the case of neutral organic molecules, the possible chemical interactions including covalent bonds, hydrogen bonding, co-ordination, ion-dipole interaction, charge transfer, acid-base reactions, and van der Waals forces can be used (Marcal et al., 2015; Tao et al., 2016). In particular, in grafting of organic moiety onto Sap, covalent bonds between surface - $\mathrm{OH}$ groups of Sap and reactive organic groups form. As such, the reactive hydrophobic organic groups durably immobilized on Sap, preventing the organic moiety from leaching (He et al., 2005; Marcal et al., 2015; Tao et al., 2016). By contrast, when organic cation-intercalated Sap is dispersed in solution, the long alkyl chain of organic cations can leach into the medium. In addition to grafting, neutral organic compounds can also form complexes with the interlayer cations of Sap (Kurokawa et al., 2014).

In the context of grafting organic moiety onto Sap, silylation, has captured particular attention. The hydroxyl groups (Si-OH-) on the external surface and/or edges of Sap can react with the silyl groups $\left(\mathrm{R}_{3} \mathrm{Si}\right)$ of silanes to form covalent bonds (Marcal et al., 2015). In particular, the broken edge of Sap possesses active Si-OH, Mg-OH and Al-OH groups (Wu et al, 2015; Honda et al, 2016; Tao et al. 2016). Namely, the active groups of Sap readily react with Si-O groups of silane and then produce silylated Sap hybrids (Herrera et al., 2004, 2005; He et al., 2014). After the edge of Sap is silylated with properly-chosen silane, then it is possible for the Sap particles to be linked by silane (Zhou and Keeling 2013).
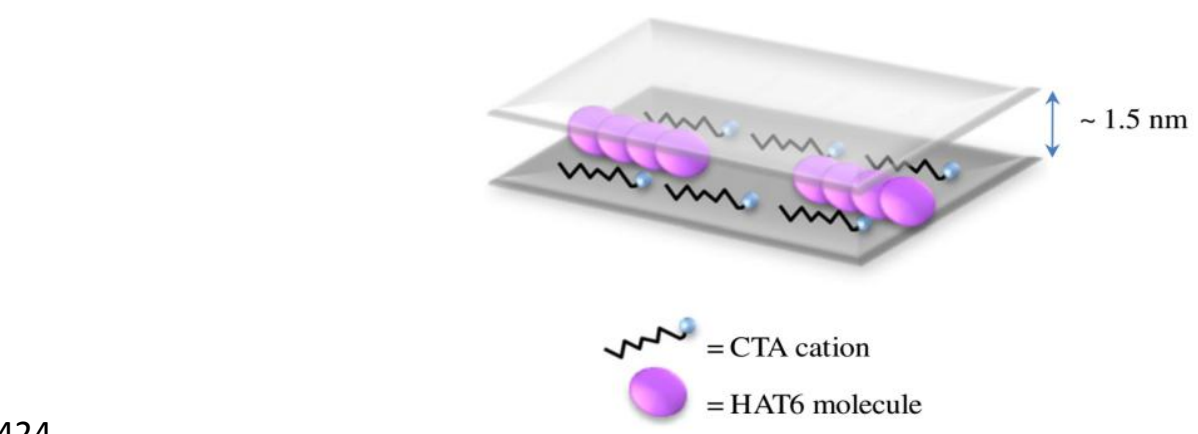

Fig. 6 Schematic drawing of the structure of CTA-HAT6-Saponite hybrid (Reprinted Nanan et al., 2015, Copyright 2015, with permission from Elsevier). CTA: Cetyltrimethylammonium cation, and HAT6: Hexakis(hexyloxy) triphenylene (a 
428

Alternatively, Sap can be firstly intercalated by organic cations, then the OSap enables neutral organic molecules to be attracted into the interlayer space by hydrophobic interaction. For example, Ishida et al. (2013) successfully prepared a supramolecular host-guest hybrid composed of a cationic organic cavitand (octaamine, OAm, host), two neutral aromatic molecules (pyrene and thracene, guests), and Sap. Due to strong Coulombic attraction between the ammonium groups of OAm and the anionic layer of Sap, the OAm was anchored to the layer of Sap. OAm can then form capsular assembly with organic neutral guest molecules. Namely, the cationic organic cavitand OAm enabled neutral organic molecules to be intercalated into the layer space of Sap. More recently, Nanan et al. (2015) successfully prepared a functional hybrid of a triphenylene-based liquid crystal molecule, hexakis(hexyloxy) triphenylene, and Sap, by the reaction between colloidal Sap in the presence of a cationic surfactant, cetyltrimethylammonium $\left(\mathrm{CTA}^{+}\right)$cation, and hexakis(hexyloxy) triphenylene (HAT6) (Fig. 6). Such findings mean that one-pot facile process for introducing cationic and neutral organic species into the interlayer space of Sap is a lot feasible.

\section{Saponite/polymer nanocomposites}

The idea of Sap/polymer nanocomposites might be borrowed from the Mt/polymer nanocomposites (Lambert and Bergaya, 2013). Similarly, the preparation of Sap/polymer nanocomposites is also achieved by solution intercalation (Jairam et al., 2013; Shin et al., 2013; Yang et al., 2013; Chang et al., 2014; Wu et al., 2014; Wang et al., 2015; Xi et al., 2015; Ju and Chang, 2016; Eguchi et al., 2017; Sas et al., 2017), melt mixing or melt intercalation (Zhen et al., 2012; Kitajima et al., 2013; Zhen and Wang, 2016) or in situ polymerization (Jairam et al., 2013; Nakamura and Ogawa, 2013; Tong and Deng, 2013; Bandla et al., 2017) (Table 3).

Table 3. Preparation and properties of typical saponite/polymer nanocomposites.

\begin{tabular}{cccccc}
\hline $\begin{array}{c}\text { Saponite } \\
\text { (Sap) }\end{array}$ & Polymer & Method & Conditions & Properties & Ref. \\
\hline raw Sap & PVA & melt mixing & $\begin{array}{c}\text { plasticizer: water and formamide; melt } \\
\text { temperature: } 115,135,125, \text { and } 110^{\circ} \mathrm{C} .\end{array}$ & $\begin{array}{c}\text { coexistence of intercalated and } \\
\text { partially exfoliated layers of }\end{array}$ & $\begin{array}{c}\text { Zhen et al. } \\
\text { (2012) }\end{array}$
\end{tabular}




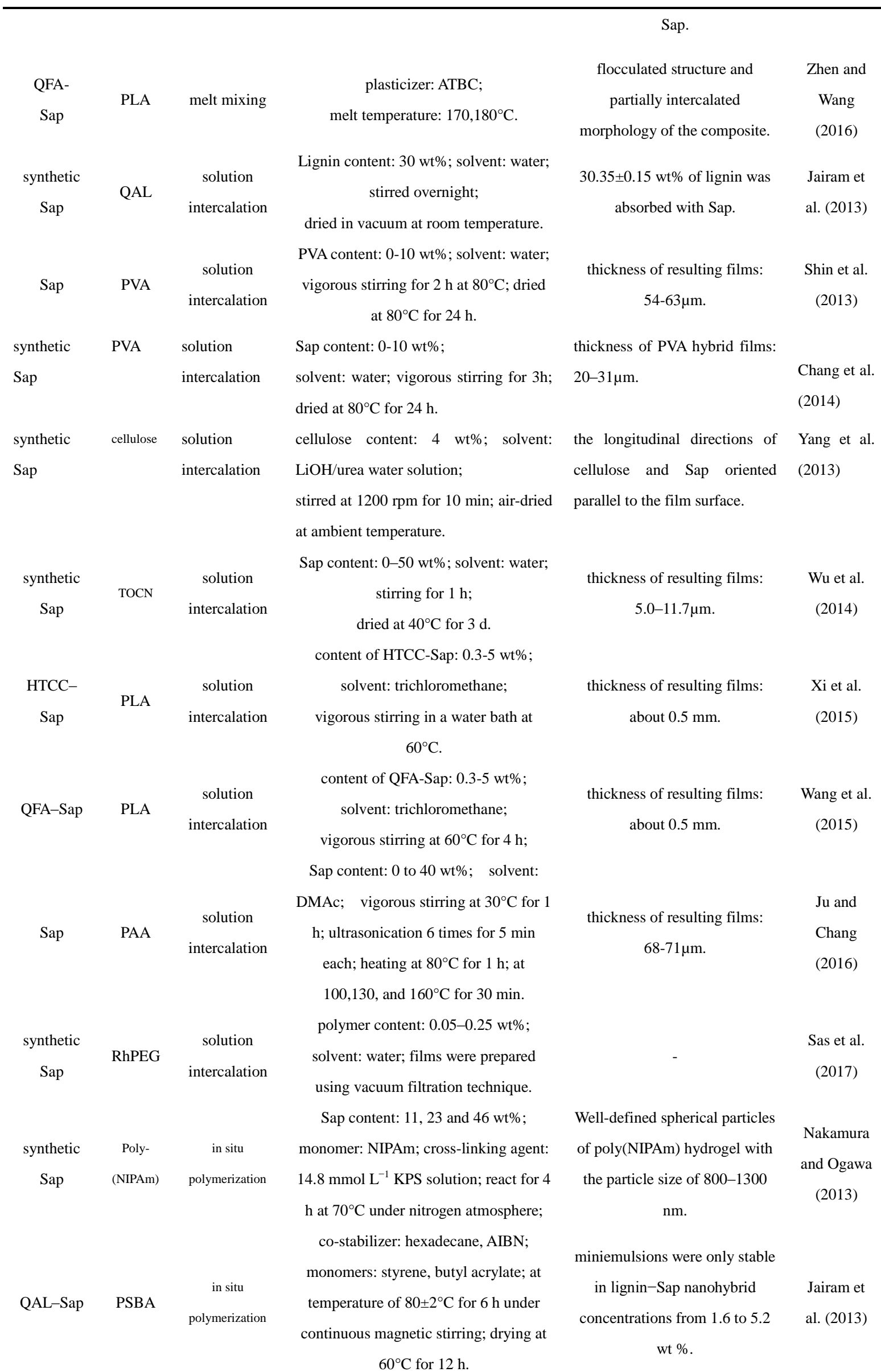




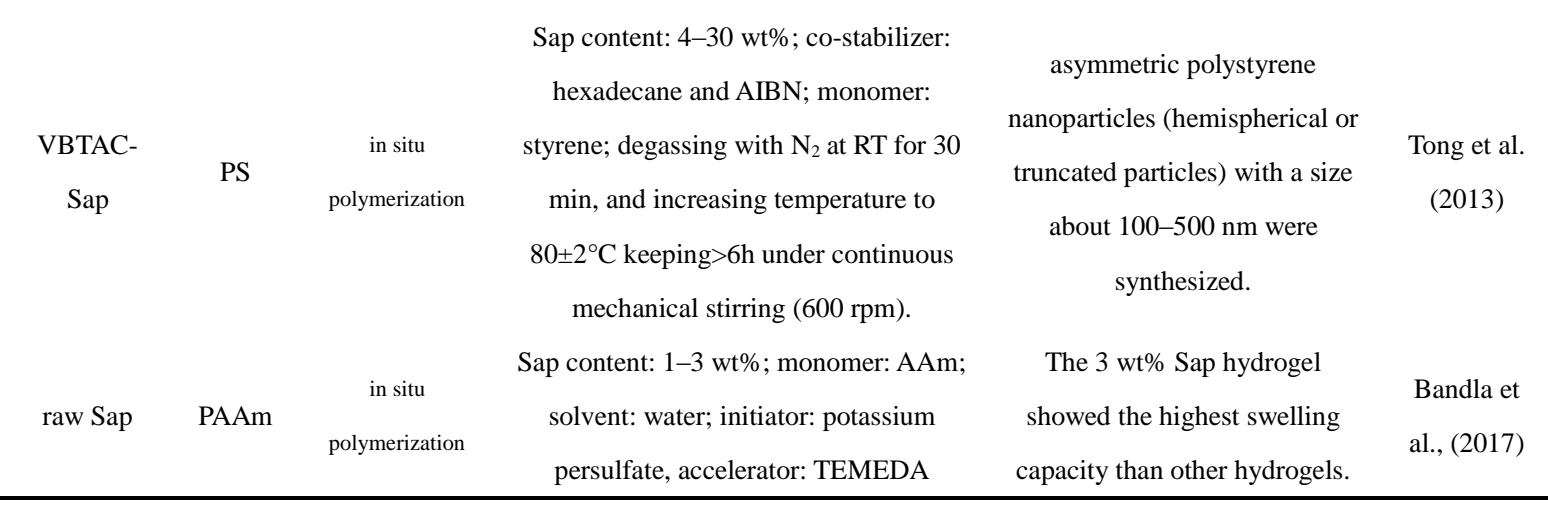

452

453

454

455

456

457

458

459

460

461

462

463

464

465

466

467

468

469

470

471

472

473

474

475

476

477

AAm: acrylamide; AIBN: 2, 2 azoisobutyronitrile; ATBC: acetyl tributyl citrate; DMAc: N, N-Dimethylacetamide; HTCC: $\mathrm{N}$-(2-hydroxyl) propyl-3-trimethyl ammonium chitosan chloride; KPS: potassium persulfate; NIPAm: N-Isopropylacrylamide; PAA: poly(amic acid); PAAm: poly acrylamide; PLA: Poly(lactic acid); poly(NIPAm): poly(N-isopropylacrylamide); PSBA: polystyrene co-butyl acrylate; PS: polystyrene; PVA: Poly(vinyl alcohol); QAL: quaternary ammonium lignin; QFA: quaternary fulvic acid; TEMEDA: $\mathrm{N}, \mathrm{N}, \mathrm{N}^{1}, \mathrm{~N}^{1}$-tetramethyl ethylenediamine; TOCN: 2,2,6,6-tetramethylpiperidinyl-1-oxyl (TEMPO)-oxidized cellulose nanofibrils; RhPEG: rhodamine B (RhB) modified polyethylene glycol (PEG); VBTAC: (ar-Vinylbenzyl) trimethylammonium chloride.

Melt mixing is the simplest method since it is easily operated, economic and environmental friendly (Shen et al., 2002; Pandey et al., 2005; Zou et al., 2008). During melt mixing, Sap is firstly mixed with thermoplastic polymers such as poly(vinyl alcohol) (PVA) and poly(lactic acid) (PLA) (Zhen et al., 2012; Zhen and Wang, 2016). The mixture is then heated to the softening point of the polymer in the presence of a plasticizer. With the mechanic force under heating, the Sap can be exfoliated and dispersed in the polymer matrix to yield a CPN. Comparatively, solution intercalation is a liquid-state process that brings about a good molecular level of mixture of Sap nanolayers and the polymer molecules (Zou et al., 2008). During this process, the soluble polymers (e.g. PVA, PLA, poly(amic acid) (PAA), polyethylene glycol (PEG)) or the dispersion of macromolecules (e.g. lignin and cellulose) in the solution are expected to be introduced into the interlayer space of Sap. Ideally, the polymers are soluble in a certain solvent such as water, aqueous alkali/urea solutions, trichloromethane, N, N-Dimethylacetamide (DMAc), etc. (Jairam et al., 2013; Shin et al., 2013; Yang et al., 2013; Chang et al., 2014; Wu et al., 2014; Wang et al., 2015; Xi et al., 2015; Ju and Chang, 2016; Eguchi et al., 2017; Sas et al., 2017). However, the solution intercalation on an industry scale could be problematic because of the use of cost-intensive solvent and its recovery (Zou et al., 2008). In in situ polymerization process, Sap is firstly dispersed into a monomer(s) solution followed by direct polymerization. In this way, the CPN are formed in situ (Jairam et al., 2013; Nakamura and Ogawa, 2013; Tong and Deng, 2013; Bandla et al., 2017). 
Whatever the process is used, an inherent issue is that ever, Sap is hydrophilic whereas polymers are mostly hydrophobic. This limits the compatibility between Sap layers and polymer chains (Jairam et al., 2013; Tong et al., 2013). Micro-phase separation often occurs in the CPN owing to the absence of interfacial interaction between Sap layers and polymer chains. As a result, the intercalation and uniform dispersion of Sap in the polymer matrix appear difficult (Wang et al., 2015; Zhen et al., 2016). Therefore, to solve these issues, it is necessary to modify the surface of Sap with organic species to increase the hydrophobicity of the surface of Sap nanolayers (Wu et al., 2014; Wang et al., 2015). In addition, the bulky organic species can expand the interlayer space of Sap, allowing easier intercalation of the polymer chains into the interlayer space of Sap (Kotal and Bhowmick; 2015) (Fig. 7).

Alternatively, the modification of polymers, instead of modification of Sap, can make the polymer chains partly hydrophilic, thereby getting compatible with Sap so that polymer chains can well penetrate into the interlayer space of Sap to produce CPN (Wu et al., 2014; Xi et al., 2015; Sas et al., 2017). For example, recently, Sas and co-workers (2017) produced a water-soluble and positively-charged polymer (RhPEG) polyethylene glycol (PEG) with a reactive rhodamine B (RhB) fluorophore and then RhPEG was successfully intercalated into the interlayer space of Sap by solution intercalation with a vacuum filtration technique. In addition, certain polymer molecules or their derivatives can be used to modify Sap first to produce OSap and such OSap is then used with other polymers to produce CPN (Jairam et al., 2013; Xi et al., 2015)
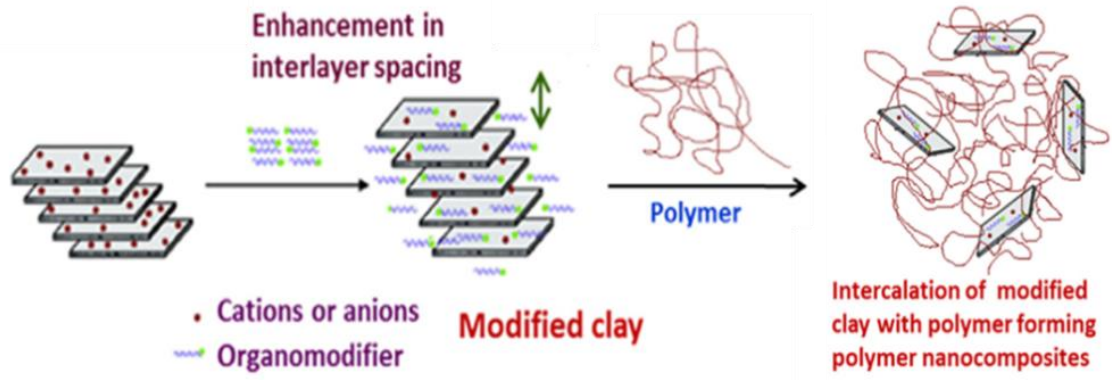

Intercalation of modified clay with polymer forming polymer nanocomposites

Fig. 7. Schematic drawing of modification of saponite followed by intercalation of polymer to form clay/polymer nanocomposites (CPN) (Reprinted Kotal and Bhowmick, 2015, Copyright 2015, with permission from Elsevier). Recently, bionanocomposites have attracted much attention (Shchipunov et al., 2012a,b; Migal, et al., 2016). The conventional methods to produce CPN cannot be directly used to produce 
Sap/biopolymer nanocomposites. Firstly, melt intercalation does not work since the majority of biopolymers suffers from degradation upon heating. Secondly, the in situ polymerization, which starts polymerization from monomers in dispersion of Sap, can also not be used, because under such a circumstance the synthesis of biomacromolecules such as polysaccharides and proteins seems impossible (Shchipunov et al., 2012a,b). In addition, Sap/biopolymer nanocomposites cannot be made by a conventional solution intercalation because the flocculation or the precipitation caused by cooperative electrostatic interactions between biomacromolecules and Sap nanoparticles, for example the oppositely charged polysaccharide and Sap nanoparticles, usually occur (Shchipunov et al., 2009).

Chitosan, natural cationic polysaccharide containing free amino groups, have been intercalated into Sap (Shchipunov and Postnova, 2010; Shchipunov et al., 2012a,b; Budnyak et al., 2016; Migal et al., 2016). Shchipunov et al. (2009) demonstrated an effective way to achieve monolithic chitosan /Sap hydrogel by shifting the $\mathrm{pH}$ of the reaction solution). The procedure to form Sap/chitosan hydrogel nanocomposites includes several steps (Fig. 8A): (1) dispersing of chitosan in an aqueous dispersion of Sap nanoparticles at a $\mathrm{pH}$ value corresponding to the neutral state of chitosan, (2) gradually acidifying the dispersion medium to make chitosan macromolecules positively charged, and (3) forming network structure via electrostatic attraction between Sap nanoparticles and chitosan macromolecules. These physical cross-linked, a three-dimensional network exhibited a gradual increase in the viscosity and finally got hydrogellation in later studies have also suggested that in such a hydrogel, part of the protonated amino groups of chitosan were electrostatically cross-linked to the oppositely charged surface of delaminated Sap nanoparticles in an aqueous solution (Shchipunov et al., 2012b; Budnyak et al., 2014). Recently, Budnyak et al. (2016) revealed that the interaction between chitosan with Sap involves both the electrostatic attraction and hydrogen bonding (Fig. 8B). It is noteworthy that this method and the chitosan/Sap system can also be used to fabricate CPN films, similar to the structure of mollusk shells (Shchipunov et al., 2012a). 


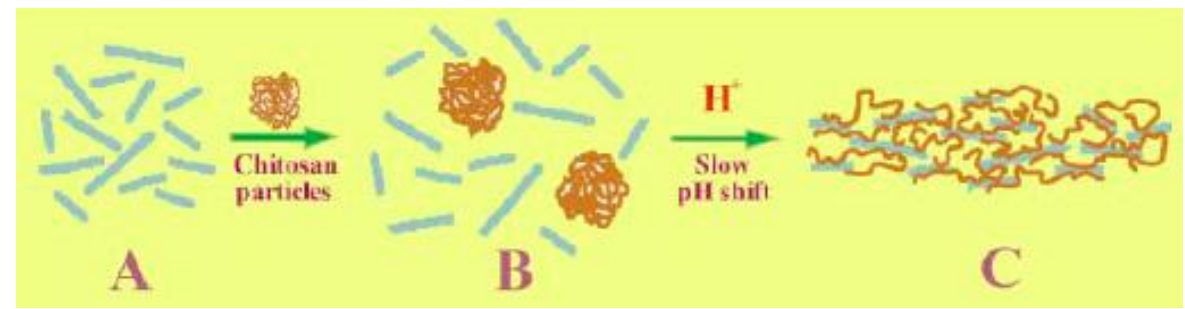

(B)

\section{Organic - inorganic hybridization}

Organic-inorganic modified Sap can be prepared through the reaction between organic species and inorganic-modified Sap, or by combining inorganic species with organic-modified Sap. The organic-inorganic modification of Sap can be achieved by the in situ polymerization of polymers in pillared Sap (Zhen et al., 2014) or pillared organic Sap (Albeniz et al., 2014; Zhen and Sun, 2014; Zhen and Zheng, 2016) and the formation of metal nanoparticles in organically modified Sap (Venkatachalam et al., 2013; Khumchoo et al., 2015; Bandla et al., 2016).

The pillaring treatment of Sap can improve cation exchange and enlarge the interlayer space of Sap, hence allowing the smooth insertion of polymer chains into the interlayer space of Sap during the preparation of CPN by in situ polymerization (Zhen et al., 2014). However, the interfacial compatibility 

between pillared Sap and the polymer is very low and the organic modification of pillared Sap can be used to solve this problem efficiently (Zhen and Sun, 2014; Zhen and Zheng, 2016). The pillared and organic pillared Sap help in eliminating the toxic effects in the in situ polymerization process of polymers and facilitate the green polymerization of polymers. Moreover, pillared and organic pillared Sap can accelerate the crystallization process of polymer matrixes, hence improving their thermal stability.

In addition, the organically modified Sap can be used to stabilize and tune the size and morphology of metal nanoparticles in the interlayer space. The interaction of the organic species and Sap layers can affect the properties of the metal nanoparticles (Venkatachalam et al., 2013; Khumchoo et al., 2015; Bandla et al., 2016). For example, Khumchoo et al. (2015) found that the photoluminescence intensities and energy of zinc oxide in CTA-Sap were controlled by the host-guest interactions of Sap and CTA. Bandla et al. (2016) presented a new process of developing silver nanoparticles via the reduction of silver ions with $\mathrm{NaBH}_{4}$ in aqueous solutions, using Sap/poly acrylamide (PAAm) nanocomposite hydrogels (Fig. 9). The AgO nanoparticle-containing hydrogel exhibited a strong antibacterial activity against two bacteria. These agents can easily find applications in wound and burn dressings. The incorporated organic compound not only entered the interlayer space of Sap, but also coated on the structural unit layer of the outer surface of Sap. In such inorganic-organic hybrids, the nanospace of Sap can be tuned by spatially controlling the number and size (molecular structure) of the organic moieties, which affects their spatial distribution (Okada et al., 2014; Marcal et al., 2015).

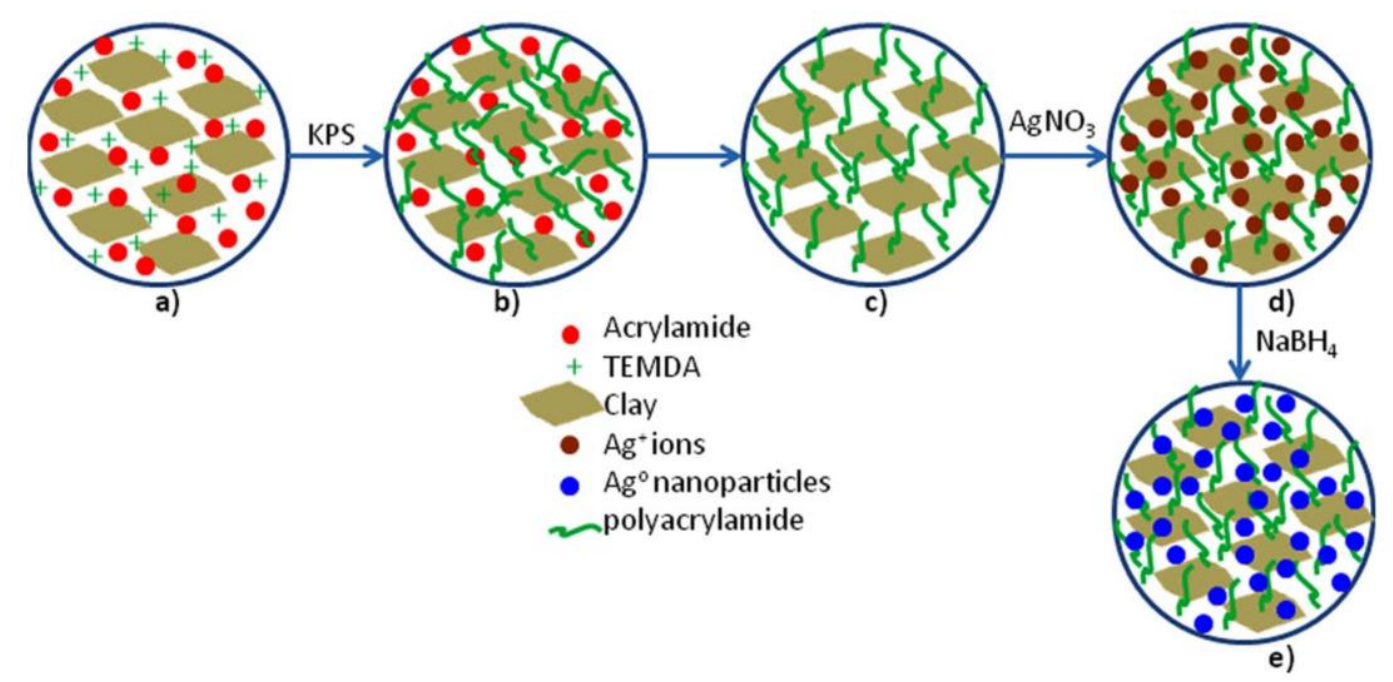


Fig. 9 Schematic representation of formation of AgO nanoparticle hydrogel (Reprinted from Bandla et al., 2017,

\section{Applications}

Earlier, Sap and its modified hybrids are often considered to be used as adsorbents (Marcal et al., 2015; Seki et al., 2015; Sato et al., 2016), catalysts and catalyst supports (Carniato et al., 2014; Fatimah et al., 2016). Over the last decades, increasing studies aim at using Sap as functional additives in CPN (Wu et al., 2014; Wang et al., 2015). It involves improving mechanical properties, gas permeability, degradation, thermal stability and flame retardancy of the CPN. More recently, Sap has also been used as a support for the immobilization of luminescent entities to prevent fluorescence from quenching by suppressing dye molecular aggregation and promoting luminescent energy transfer between donor and acceptor dye pairs inside the interlayer space of Sap. In addition, dye molecules may exhibit unique optical imaging (Tsukamoto et al., 2016b) and optoelectronic properties (Nanan et al., 2015).

\section{5}

\subsection{Optical materials}

Among clay minerals, Sap could be the most ideal host materials for the immobilization of luminescent entities. Firstly, Sap easily delaminates to single nanolayers in water. Secondly, such an aqueous dispersion of Sap is transparent in the range of UV-visible light. Thirdly, Sap itself is not photo or redox active (Tsukamoto et al., 2016b). Fourthly, many luminescent organic dye molecules or cations can be facilely introduced into the interlayer space of Sap to produce clay-based nanocomposites. In this way, the aggregation of luminescent entities can be controlled so their luminescent intensity can be stabilized or enhanced. In addition, the luminescent energy transfer between donor and acceptor dye pairs in the interlayer space of Sap can be promoted. Thus the resultant clay-based nanocomposites exhibit unique optical properties.

During fabricating luminescent materials, the aggregation of luminescent dye molecules often occurs. The formation of irregular aggregates, such as $\mathrm{H}$-aggregates, which are sandwich-type structured molecular assemblies (Donauerová et al., 2015), significantly decreases the excited-state lifetime of luminescent dye molecules. Moreover, irregular aggregates could lead to fluorescence 
quenching or lower photoactivity (Takagi et al., 2013; Bujdák et al., 2016). Hence, suppressing the

600

601

602

603

604

605

606

607

608

609

610

611

612

613

614

615

616

617

618

619 aggregation of luminescent dye molecules is a critical issue. Saponite has a rigid structure and can provide a confined microenvironment to luminescent molecules on a nanoscale. Hence, in the interlayer space of Sap, J-aggregates with a more open geometry in which the luminescent dye molecules better contact with the surface of Sap become favorable (Epelde-Elezcano et al., 2016). A good dye distribution in the interlayer space of Sap can be achieved reducing molecular aggregation. The net negative charge at the external tetrahedral sheet in the films of Sap permits strong electrostatic Sap-dye interactions in a dye molecule/Sap hybrid. These interactions are conducive to suppressing dye molecule aggregation. They can also increase luminous intensity of the dye molecules and extend the fluorescence lifetime (Wu et al., 2015; Epelde-Elezcano et al., 2016; Boháč et al., 2016; Bujdák et al., 2016). In addition, in a confined microenvironment of the interlayer space of Sap, the dye molecules have to occur in a parallel orientation with respect to the surface of the Sap nanoparticles (Tominaga et al., 2017) (Fig. 10). Moreover, dye molecules in the interlayer space of Sap may undergo a conformational change when the thickness of the intercalated molecule is larger than the interlayer spacing of the Sap. Such intercalation renders a pseudo uniaxial pressure to an organic molecule under ordinary temperature and pressure. In a high hydrostatic pressure field, the organic molecule favors a planar conformation. Intercalating the fluorescence dye into the interlayer space of Sap represents a promising progress in developing inorganic-organic luminescent hybrid films of high performance.

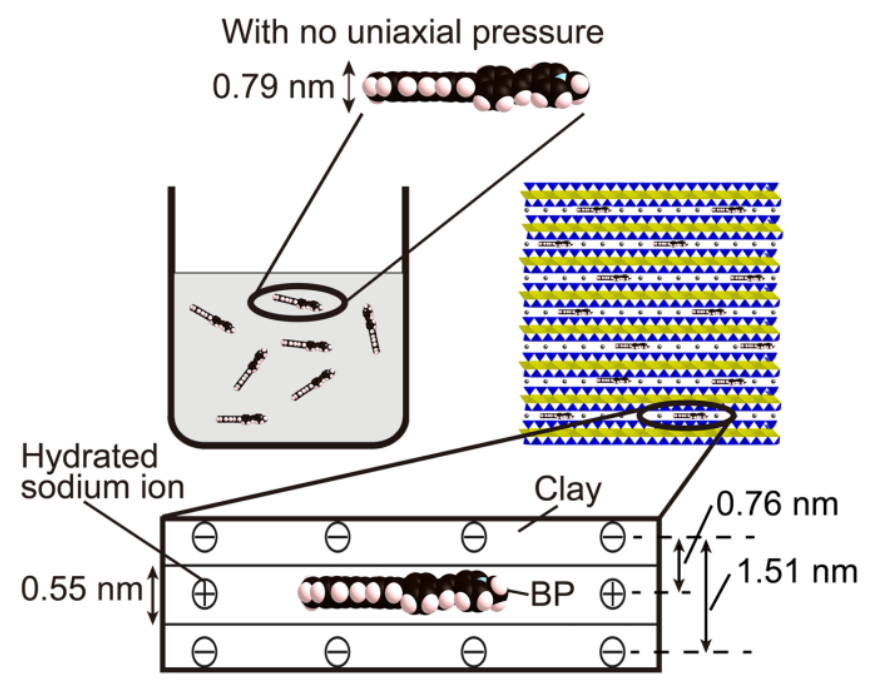


Aggregation of luminescent dye molecule can be further tuned by the co-adsorption of alkylammonium cations because they compete with dye cations for adsorption sites, thereby isolating each dye molecule and suppressing the aggregation (Belusăkova et al., 2015; Donauerová et al., 2015; Epelde-Elezcano et al., 2016). In other words, co-intercalation of alkylammonium cations in the interlayer space of Sap allows potential fluorescent J-aggregates rather than undesirable H-aggregates (Epelde-Elezcano et al., 2016). It is noteworthy that the layer charge of Sap and the solvents also remarkably affect the aggregation of luminescent dye molecule in the interlayer space, hence influencing the properties of the Sap/dye hybrids (Wu et al. ,2015; Czímerová et al., 2017). molecule (Calzaferri, 2012; Verma and Ghosh, 2012; McLaurin et al., 2013). The process plays a critical role in natural and artificial photochemical processes such as photosynthesis, photo-sensitized molecular transformation and solar cells (Gust et al., 2009; Hasobe, 2013). Intercalating luminescent cationic dye species in the confined interlayer space of Sap can promote Förster resonance energy transfer (FRET) between donor and acceptor dye pairs (Ishida et al., 2013; Olivero et al., 2014; Sato et al., 2014b; Belušáková et al., 2015; Goto et al., 2015; Fujimura et al., 2016; Tsukamoto et al., 2016a;

641 Belušáková et al., 2017). In addition, FRET is sensitive to surface concentration, which could be easily controlled by an appropriate selection of the dye/Sap ratio (Belušáková et al., 2017). Promoting FRET

643 between donor and acceptor dye pairs in the interlayer space of Sap provide a new way for developing new artificial light harvesting systems. 

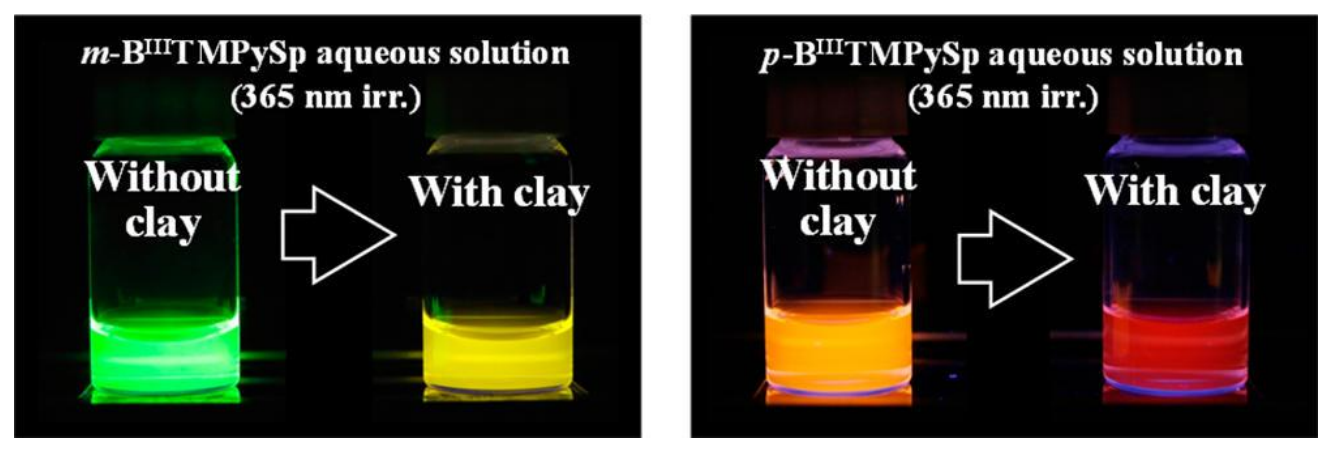

(B)

649
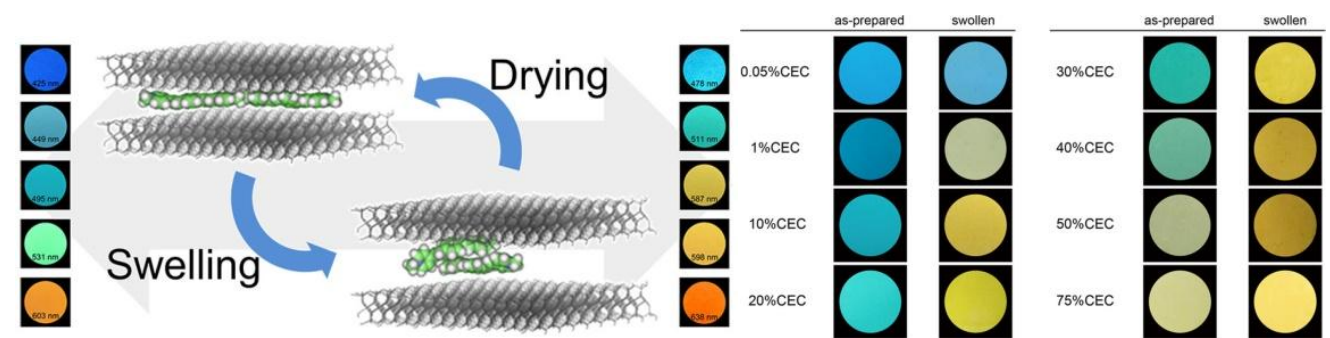

Fig. 11. (A) Changes in fluorescence color of $m-B^{\mathrm{II}} \mathrm{TMPySp}$ and $\mathrm{pB}^{\mathrm{II}} \mathrm{TMPySp}$ without and with the saponite excited at $365 \mathrm{~nm}$ in water. [subporphyrin] $=2.7 \times 10^{-6} \mathrm{M}(0.4 \%$ versus CEC of the saponite) (Reprinted with permission from Tsukamoto et al., 2016b. Copyright (2016) American Chemical Society). (B) Fluorescence colors of saponite-DPDP hybrid films with various \% CEC loading. Left and right columns correspond to the as-prepared and swollen states, respectively. DPTP:4,4'-[4,1-phenylenedi-2,1-ethynediyl]bis[1-methylpyridinium] diiodide (Adapted and reprinted with permission from Tominaga et al., 2016. Copyright (2016) American Chemical Society)).

Luminescent dye-Sap complexes can act as highly sensitive sensors and can be used in artificial photosynthesis systems (Tominaga et al., 2016; Tsukamoto et al., 2016b; Ogawa et al., 2017). For example, Tsukamoto et al. (2016b) intercalated two types of meso-substituted +3-charged subporphyrin derivatives having m-methylpyridinium and p-methylpyridinium (m-B ${ }^{\mathrm{III}} \mathrm{TMPySp}$ and $\left.\mathrm{p}-\mathrm{B}^{\mathrm{III}} \mathrm{TMPySp}\right)$ into the interlayer space of Sap. The photo- or optical properties, with and without the anionic layers of Sap of the two subporphyrin derivatives proved to be different. The absorption and fluorescence spectra of subporphyrin-Sap complexes shifted to longer wavelengths because of luminescent molecules lying flat on the surface of Sap. Changes in fluorescence color of $\mathrm{m}-\mathrm{B}^{\mathrm{III}} \mathrm{TMPySp}$ and $\mathrm{pB}^{\mathrm{III}}$ TMPySp without and with the Sap excited at $365 \mathrm{~nm}$ in water can be observed (Fig. 11A). Tominaga et al. (2016) prepared chromic hybrid films consisting of fluorescent organic molecules with planar $\pi$-conjugated systems and synthetic Sap. The swelling and drying of Sap can reversibly switching fluorescence color (Fig. 11B). In the hybrid films, the organic molecules formed an excimer in the swollen interlayer space of Sap, whereas they were a monomer in the dried interlayer space. The emission wavelengths of the excimer and monomer were different, leading to the switching 
fluorescence color of the hybrid films. Formation and deconstruction of the excimer can be controlled under a mild external stimulus. Moreover, the color switching can be repeated for many cycles. The findings imply that both the confined microenvironment by the interlayer space of the Sap and the reversible swellability can be used for switching optical properties of the resultant hybrids and such intelligent methodology and mentality can be extended to make many other smart materials with switchable properties.

\subsection{Adsorbents}

Saponite can be used as cation exchangers and adsorbents to remove radioactive ions in nuclear wastes (Srinivasan, 2011; Sato et al., 2016; Adraa et al., 2017; Sato and Hunger, 2017). It can also be applied to separation of heavy metals from wastewater and fixation of the hazardous cations in soil (Budnyak et al., 2016; Franco et al., 2016a; Petra et al., 2017). After organic modification of Sap, the affinity of OSap for organic species is increased and thus can be used to remove dyes and pigments from wastewater (Nakamura and Ogawa, 2013; Makarchuk et al., 2016; Tangaraj et al., 2017). It can also be used to remove carcinogens from foods and food additives (Seki and Ogawa, 2010; Carraro et al., 2014; Marcal et al., 2015; Okada et al., 2015; Seki et al., 2015).

\subsubsection{Adsorption of metallic cations}

Heavy metal pollution is a severe problem and threatens ecological systems and human health. Typically, nowadays with the increasing relevant mining and uses of the heavy metal resources. Some waters, groundwater and soil have been polluted by $\mathrm{Cd}^{2+}, \mathrm{Cu}^{2+}, \mathrm{Hg}^{2+}$, and $\mathrm{Pb}^{2+}(\mathrm{Cruz}-\mathrm{Guzmán}$ et al., 2012; Yang et al., 2016; Zhu et al., 2016). Numerous methods for handling the pollution of the heavy metals have been reported in the literature, but little is satisfactory, in view of the high expenses and low efficiency (Padilla-Ortega et al., 2016).

Over last few years, the use of inorganically pillared, organically modified, chemical and mechanochemical activated Sap has been studied to adsorb and fix heavy metal cations. Franco et al. (2016a) evaluated the effectiveness of adsorption of heavy metal cations $\left(\mathrm{As}^{3+}, \mathrm{Cd}^{2+}, \mathrm{Cr}^{3+}, \mathrm{Cu}^{2+}, \mathrm{Hg}^{2+}\right.$, $\mathrm{Ni}^{2+}, \mathrm{Pb}^{2+}$ and $\left.\mathrm{Zn}^{2+}\right)$ at very low concentrations (10-100 ppb) by natural Sap and Fe-pillared and Al-pillared Sap, aiming at purifying the drinking water. Natural Sap and pillared Saps showed notably 
higher adsorption capacities of those cations except $\mathrm{Hg}^{2+}$ than carbon used as a reference. In particular, both natural and pillared Sap appeared to be highly efficient to adsorb $\mathrm{Cr}^{3+}$. The adsorption capacity is in the order: Fe- pillared Sap> natural Sap> Al-pillared Sap. Recently studies have shown that Sap/chitosan nanocomposites can act as efficient adsorbents for the removal of heavy metals from polluted water. The adsorption behavior is influenced by the $\mathrm{pH}$ value of the medium, contact time, and initial metal ion concentration (Budnyak et al., 2016). For such nanocomposite, in addition to the interlayer space of Sap to adsorb the cations, the adsorption can occur through complexation of aqua, acetic, or bi-ligand complexes of the cations with amino groups of chitosan and such formation of complexes heavily depends on the $\mathrm{pH}$ value of the medium, namely, acidic basic and neutral one.

Besides chemical modification, mechanochemical activation by high-energy ball milling or grinding have recently been demonstrated to activate Sap for effective fixation of heavy metal cations. Comparatively speaking, mechanochemical activation is a relatively low-cost, effective, and green method to practical application. Such activated Sap can be produced effectively in a planetary ball mill, where the impact energy arising from the ball to ball and ball to wall collisions is transferred to the Sap powder. Such mechanochemical activation can substantially produce fresh and active surfaces for Sap particles. As a result, the surfaces are active for adsorbing heavy metal cations (Vdović et al., 2010). Owing to the existence of many $-\mathrm{OH}$ groups on the surface of Sap, the adsorbed metal cations can form insoluble hydroxides on the surface of Sap. Hence the cations are well fixed. More recently, Petra et al. (2017) disclosed that the adsorption for $\mathrm{Cu}^{2+}$ by activated Sap was more efficient than for $\mathrm{Ni}^{2+}$. Nevertheless, for producing effective Sap adsorbents for fixation of heavy metals, tedious screening for the types of metal cations, condition and the modification of Sap remain necessary and challenging.

Earlier studies have revealed that radioactive Cs firmly stays on Sap in soil or water (Kim and Kirkpatrick, 1997; Mcbride, 1997; Sato et al., 2016; Dzene et al. 2017). 2D nanolayered Sap can form several types of structures and provide several types of sites for adsorption (Fig. 12) (Sato and Hunger, 2017). The adsorption can occur at the external surfaces (oxygen plane), the broken-bond edges, the wedge-shaped parts, the surfaces in the oncoming hexagonal cavities, and the surfaces in the hexagonal cavities. Consequently, at different sites, the amount and the strength of adsorption appear different due to the different geometrical confinement, physisorption, and chemical bonds. The edges can significantly contribute to the Cs adsorption, along the oxygen planes. Both the oxygen planes and the edges of Sap should be used as the active sites for adsorbing and decontaminating radioactive 
Cs. Such subtle analysis and findings have much deepened into the insights into the adsorption of Sap for radioactive elements. Finally, it should be pointed out that few studies are reported on the adsorption of radioactive $\mathrm{U}, \mathrm{Th}$ and $\mathrm{Pu}$ ions from nuclear wastes. These elements are more practically used for nuclear energy, so such studies could be more needed (Bian, et al., 2015).

(I)

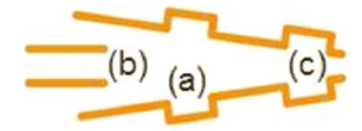

(III)

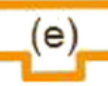

(II)

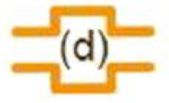

(IV)

(b)

Fig.12 Schematic drawings of local molecular structures formed by 2D nanolayers in the dehydrated state: (I)

two-nanolayer insertion type, (II) oncoming hexagonal cavities, (III) hexagonal cavities, and (IV) steps. Cs adsorption

occurs at (a) surfaces, (b) edges, (c) wedge-shaped parts, (d) surfaces in the oncoming hexagonal cavities, and (e) surfaces

in the hexagonal cavities (Adapted and reprinted from Sato and Hunger, 2017, with permission from the PCCP Owner

Societies).

\subsubsection{Removal of carcinogens and caffeine}

In addition to cation species, the adsorption of nonionic species is also possible through ion-dipole interactions and hydrogen bonding (Theng, 1974). When the cations in the interlayer space of Sap are replaced with organic cations, the surface of the resultant Sap become active for the adsorption of various ionic and nonionic organic species (Ogawa, and Kuroda, 1997). The applications of Sap based on the adsorption is now expanded to the selective adsorption and removal of carcinogens and additives from foods and plants. 2-phenylphenol (also known as 2-hydroxybiphenyl, 2PP) is an antifungal agent used for oranges. On-site removal of 2PP by organically-modified Sap can improve the safety of fresh orange juice (Seki and Ogawa, 2010). Even in the presence of sucrose in the starting aqueous solution, 2PP can also be selectively adsorbed on organically-modified Sap. Interestingly, Seki et al. (2015) found that the removal of 2PP by CONH-modified Sap (CONH-Sap) from aqueous sucrose solution 
was even more efficient than that from the solution without sucrose. Monolayer 2PP adsorption to CONH-Sap reached $0.067 \mathrm{~g} / \mathrm{g}$ in the presence of sucrose and $0.062 \mathrm{~g} / \mathrm{g}$ in the absence of sucrose. The basic reason is ascribed to the difference in the $2 \mathrm{PP}$ solubility in water and in aqueous sucrose solution.
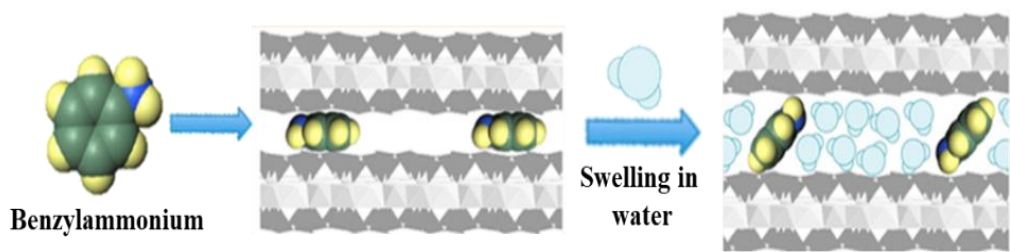
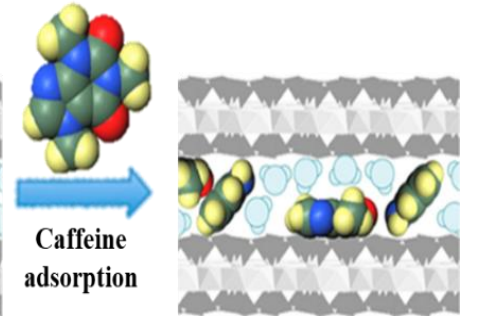

\section{Fig. 13 Schematic drawing of the process of preparation of benzylammonium (BA)-saponite and the adsorption of}

caffeine over water dispersed BA-saponite (Reprinted and adapted with permission from Okada et al., 2015, Copyright (2015)

American Chemical Society).

The large consumption of coffee worldwide has made caffeine a chemical marker or indicator of water pollution. Microorganisms in wastewater usually cannot metabolize the compound effectively. Recently, OSap can act as an efficient adsorbent of caffeine. Adsorption capacity depends primarily on the intercalated organic cations. For example, Okada et al. (2014) have clearly demonstrated the enhanced adsorption of caffeine in water on benzylammonium (BA)-modified Sap (BA-Sap, respectively) (Fig. 13). By contrast, CONH-Sap adsorbed less caffeine than raw Sap and BA-Sap. It was suggested that BA enlarges the siloxane surface area of Sap and make it more available for the adsorption of caffeine. The interlayer space of BA-Sap is further expanded significantly in water by the intercalation of water molecules into it, making the nanospaces suitable for accommodating caffeine molecules. By interacting with BA, the siloxane in the layers of the Sap plays an important role in caffeine adsorption. Marcal et al. (2015) found that CTAB- and APTS-modified synthetic Sap are also efficient absorbents for the adsorption of caffeine from aqueous solutions. The kinetic studies the adsorption fitted into the pseudo-second-order equation, implying that chemical adsorption controlled the process. Comparatively, APTS-Sap exhibited a high affinity for caffeine and possessed a maximum adsorption capacity of $80.54 \mathrm{mg} / \mathrm{g}$ after $4 \mathrm{~h}$. The above studies indicated that Sap-based 
materials are promising candidates for the selective adsorption and removal caffeine from aqueous solution.

\subsubsection{Removal of dyes and pigments from wastewater}

Dyes and pigments are widely used in the textiles, paper, plastics, leather, and cosmetic industries for coloring products. Most dyes and pigments are toxic and not biodegradable, so they need to be removed from wastewater in industry (Hashemian et al., 2015). A wide range of physicochemical and biological methods for removing dyes and pigments from wastewaters have been studied. The adsorption process proves more effective (Bhatnagar and Sillanpää, 2010). In recent years, there has been increasing interest in using OSap to adsorb organic molecules of dyes and pigments (Rafatullah et al., 2010; Nityashree et al., 2014).

As always, the organic modification of Sap increases its affinity for dyes. The OSap can also be made into hydrogel for adsorption. For example, Nakamura and Ogawa (2013) examined the adsorption of a cationic dye (rhodamine 6G) on the spherical particle of a Sap-containing poly(N-isopropylacrylamide) hydrogel. The cation adsorption capacity of the hybrid hydrogel particles was mainly determined by the cation exchange capacity of Sap. Tangaraj et al. (2017) investigated the adsorption capacities of CTA-Sap with three fluorescent dyes, namely Rhodamine 640 perchlorate rhodamine (Rho), sulforhodamine B (SR), and Kiton red 620 (KR). The edges and faces of Sap particles was found responsible for the adsorption of dyes. The adsorption isotherms fitted well into the non-linear Langmuir isotherm model. Most of the dye molecules can be released in aqueous solution. Another issue is that after adsorption, the separation of Sap particles from the aqueous solution are considerable difficulty due to their easy delaminate and high dispersion. To overcome this, a suggested method is to endow saponite particles with magnetic properties (Chen et al., 2016). As a result, magnetized Sap can be separated by the simple procedure of magnetic separation and removed from the water (Xu et al., 2012; Giakisikli and Anthemidis, 2013). Moreover, magnetite/Sap nanocomposites can possess a microporous and mesoporous structure and thus have enhanced adsorption performance in comparison to Sap alone and magnetite alone (Makarchuk et al., 2016). 
805
A

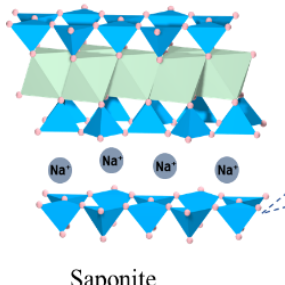

Saponite

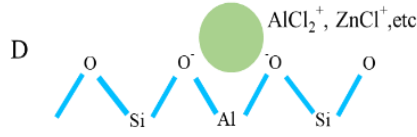

Supported Lewis acid

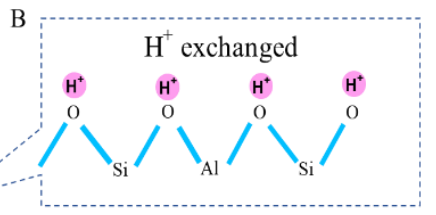

tetrahedral sheet

E

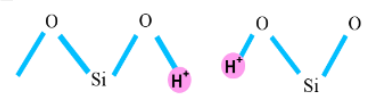

Brønsted acid (esp. by acid treatment)
C

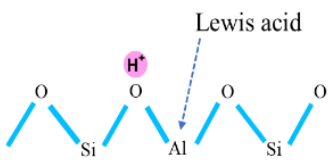

Brønsted acid

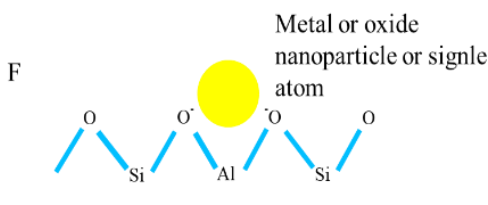

Redox acive centers

Fig. 14 Schematic drawing of Brønsted acid, Lewis acid and redox sites on saponite catalyst or saponite-supported

catalyst.

Over the past few decades, many strategies have been developed to produce clay minerals-based catalysts (Zhou, 2011). In the layer of Sap, isomorphous substitution of some $\mathrm{Si}(\mathrm{IV})$ by $\mathrm{Al}(\mathrm{III})$ in the tetrahedral sheet not only make the layer to be negatively charged but also creates Lewis acidity. The exchangeable cations in the interlayer space of Sap, typically $\mathrm{Na}^{+}, \mathrm{K}^{+}$, and $\mathrm{Ca}^{2+}$, which compensate the layer charge, can be exchanged with $\mathrm{H}^{+}$, thereby creating Brønsted acidity (Fig. 14B). Besides, more Brønsted acid sites can be created through $\mathrm{H}^{+}$coordination or silanol group $-\mathrm{Si}-\mathrm{O}-\mathrm{H}^{+}$(Fig. 14C). Such acidity can be enhanced by proper acid treatment of Sap to partly remove $\mathrm{Al}$ and create more edges or broken bonds (Fig. 14E). Many studies have proved that $\mathrm{Al}$ in the tetrahedral sheet exhibits Lewis acidity. In addition, two-dimensional nanolayer possesses the large surface and the surface can be used to support Lewis acid reagents like $\mathrm{AlCl}_{3}, \mathrm{ZnCl}_{2}$ and $\mathrm{FeCl}_{3}$ (Fig. 14D). Such Sap prove to be an efficient catalyst for acid-catalyzed organic reactions, for example the synthesis of $\beta$-amino ketones via Mannich-type reactions under mild conditions (Gómez-Sanz et al., 2017). In addition, the synthesis of Sap can be easily adapted to introduce some metal or metal oxide centers in the octahedral or tetrahedral sheet of Sap so that the M-Sap are able to catalyze redox reactions (Fig. 14F). Moreover, due to its easily and controllably expandable interlayer space with large surface area, Sap can also be used as catalyst supports. (Table 4) 
Table 4. Catalytic activity of saponite (Sap) and Sap supported catalysts.

\begin{tabular}{|c|c|c|c|c|c|c|c|}
\hline Catalyst & Reaction & $\begin{array}{c}\mathrm{S}_{\mathrm{BET}} \\
\left(\mathrm{m}^{2} / \mathrm{g}\right)\end{array}$ & $\begin{array}{c}\mathbf{T} \\
(\mathbf{K})\end{array}$ & (h) & $\begin{array}{c}\text { Conversion } \\
(\%)\end{array}$ & $\begin{array}{l}\text { Yield } \\
(\%)\end{array}$ & Ref. \\
\hline $\begin{array}{l}\text { Cs }(1.25 \mathrm{wt} \%) / \mathrm{Al}_{13} \\
\text {-pillared Sap }\end{array}$ & $\begin{array}{c}\text { Synthesis of } \\
\text { N-alkyl pyrazoles }\end{array}$ & 47 & 353 & 1 & 100 & 100 & $\begin{array}{l}\text { Velasco et al. } \\
\text { (2011) }\end{array}$ \\
\hline $\mathrm{Ni}(20 \mathrm{wt} \%) / \mathrm{Sap}$ & $\begin{array}{l}\text { Hydrogenation of } \\
\text { styrene oxide }\end{array}$ & RT & 344 & 1 & 100 & 100 & $\begin{array}{l}\text { Vicente et al. } \\
\text { (2011) }\end{array}$ \\
\hline $\begin{array}{c}\text { MgFe-Sap } \\
\text { NiMgAl-Sap }\end{array}$ & $\begin{array}{l}\text { Epoxidation of } \\
\text { (Z)-cyclooctene by } \\
\text { hydrogen peroxide }\end{array}$ & $\begin{array}{l}467 \\
334\end{array}$ & RT & 48 & $\begin{array}{l}7.5 \\
8.8\end{array}$ & $\begin{array}{l}7.5 \\
8.8\end{array}$ & $\begin{array}{l}\text { Trujillano et } \\
\text { al. (2011) }\end{array}$ \\
\hline $\begin{array}{c}\text { Acid activated } \\
\mathrm{V}(0.05 \mathrm{mmol} / \mathrm{g}) / \mathrm{Sap}^{1}\end{array}$ & $\begin{array}{l}\text { Oxidative } \\
\text { dehydrogenation of } \\
\text { propene into coke }\end{array}$ & - & 773 & 0.5 & 21 & - & $\begin{array}{l}\text { Ostinelli et al. } \\
\text { (2012) }\end{array}$ \\
\hline $\begin{array}{l}\text { Zirconia-cluster } \\
\qquad \begin{array}{c}(1 \mathrm{mmol} / \mathrm{g}) / \\
\text { Sap }\end{array}\end{array}$ & $\begin{array}{l}\text { Isomerization of } \\
\text { 1-butene }\end{array}$ & 410 & 573 & 2.5 & 82 & - & $\begin{array}{c}\text { Kameshima et } \\
\text { al. (2013) }\end{array}$ \\
\hline $\mathrm{Nb}^{\mathrm{V}} / \mathrm{Sap}$ & $\begin{array}{c}\text { Oxidative abatement } \\
\text { of } \\
\text { CEES }\end{array}$ & - & 298 & 8 & 98 & $71.5^{*}$ & $\begin{array}{l}\text { Carniato et al. } \\
\text { (2014) }\end{array}$ \\
\hline $\begin{array}{c}\mathrm{TiO}_{2}(0.42 \mathrm{~g} / \mathrm{L}) \\
/\left[\mathrm{Ru}(\mathrm{bpy})_{3}\right]^{2+}-\mathrm{Sap}\end{array}$ & $\begin{array}{l}\text { Oxidation of benzene } \\
\text { to phenol }\end{array}$ & - & VIS & 5 & 72 & 69 & $\begin{array}{c}\text { Goto and } \\
\text { Ogawa } \\
(2016)\end{array}$ \\
\hline $\mathrm{ZnO} / \mathrm{Sap}$ & $\begin{array}{l}\text { Photocatalytic } \\
\text { decomposition of } \\
\text { Methylene Blue }\end{array}$ & 168 & UV & 3 & 93 & - & $\begin{array}{c}\text { Khumchoo et } \\
\text { al. (2016) }\end{array}$ \\
\hline $\begin{array}{c}\text { Sulphated zirconium } \\
\text { pillared Sap }\end{array}$ & $\begin{array}{l}\text { Conversion of } \\
\text { citronellal }\end{array}$ & $190^{*}$ & MW & $\begin{array}{l}10 \\
\min \end{array}$ & 100 & - & $\begin{array}{l}\text { Fatimah et al. } \\
\qquad(2016)\end{array}$ \\
\hline $\mathrm{Cu}(5 \mathrm{wt} \%) / \mathrm{Na}-\mathrm{Sap}$ & $\begin{array}{l}\text { Diesel soot } \\
\text { combustion }\end{array}$ & - & 673 & - & 100 & 99 & $\begin{array}{c}\text { Gebretsadik et } \\
\text { al. (2016) }\end{array}$ \\
\hline $\mathrm{Ni}(40 \mathrm{wt} \%) / \mathrm{H}-\mathrm{Sap}$ & $\begin{array}{c}\text { Glycidol } \\
\text { hydrogenolysis to } \\
\text { 1,3-propanediol }\end{array}$ & 229 & 453 & 1 & 100 & 29 & $\begin{array}{c}\text { Gebretsadik et } \\
\text { al. (2017b) }\end{array}$ \\
\hline
\end{tabular}


$\operatorname{Re}(7 \mathrm{wt} \%)$ modified $\mathrm{Ni}$

Glycidol

$(40 \mathrm{wt} \%) /$

hydrogenolysis to

331

393

4

98

46.1

Gebretsadik et

acid Sap

1,3-propanediol

Synthesis of $\beta$-amino

Raw Sap

ketones by Mannich

13

318

80

Gómez-Sanz reaction

835

* For clarity, consistency, and easy comparison, some original data have been rounded off.

T: Temperature; t: Time; VIS: Visible light irradiation; UV: UV irradiation; MW: Microwave irradiation; RT: Room temperature; CEES: (2-chloroethyl)ethyl sulfide.

The incorporation of transition elements, such as Ni (Trujillano et al., 2011), Fe (Trujillano et al., 2011), V (Ostinelli et al., 2012), and Nb (Carniato et al., 2014), into the framework of Sap, including acid activated Sap, allows the combination of high surface area and porosity of the Sap with the solid acidic and redox catalytic active centers. Theoretically, the transition metal atoms can be incorporated in the octahedral or tetrahedral sheets of Sap. When transition elements are introduced into the tetrahedral sheet of Sap, the co-existence of active transition metal cations, for example V (Ostinelli et al., 2012) and $\mathrm{Nb}$ cations (Carniato et al., 2014), and the tetrahedral silicon cations, a synergetic effect of the redox properties of the transition metals and the Brønsted acid sites makes the transition metal-containing Sap an effective catalyst (Ostinelli et al., 2012; Carniato et al., 2014). Recent studies demonstrated that the transition metal-containing Sap can be used to catalyze the epoxidation of (Z)-cyclooctene by hydrogen peroxide (Trujillano et al., 2011), the conversion of propene into coke (Ostinelli et al., 2012) and the oxidative abatement of chemical warfare agents (Carniato et al., 2014). Moreover, the active cations in the framework of Sap could be more stable and leaching of the active metallic cations during catalytic reaction in a liquid phase can be mitigated to some extent (Trujillano et al., 2011). Pillaring treatments of Sap can increase the SSA, the pore volume and the surface acidity and re-dox catalysis of Sap. In particular, pillars in the pillared Sap can be designed and made with additional specific catalytic performances (De Stefanis et al., 2013; Zhen et al., 2014; Zhen and Zheng, 2016). In pillared Sap, the major sources for Brønsted and Lewis sites are associated with the lattice hydroxyls of Sap and the pillars in the interlayer space of Sap. For example, Kameshima et al. (2013) successfully prepared zirconia-cluster pillared Sap and revealed that both the amounts of Brønsted and Lewis acids remarkably increased after pillaring Sap with zirconia-cluster. The zirconia-cluster was a main source for generating Lewis acidity besides the tetra-coordinated $\mathrm{Al}$ in the tetrahedral sheet of Sap 
while Brønsted acidity was provided by $\mathrm{H}^{+}$coordination and silanol group generated by removal of some Al from the tetrahedral sheet of Sap (Fig. 14E). Recently, regarding sulphated zirconia-pillared Sap, Fatimah et al. (2016) discovered that the sulphate anions on the surface can increase the number and strength of the Brönsted acid sites of zirconia-pillared Sap.

Saponite, acid activated Sap, pillared Sap, and other related hybrids can also be used as a catalyst support. The support offers expandable interlayer space, high SSA, surface acidity, and good thermal stability (Garciano et al., 2014; Gebretsadik et al., 2016; Khumchoo et al., 2016). In particular, in view of synthesis, swellability, surface acidity, and thermal stability, Sap has an advantage over Mt. Such Sap-supported catalysts can catalyze a wide range of reactions. Recent examples are Cs/Al-pillared Sap catalysts for the synthesis of $\mathrm{N}$-alkyl pyrazoles (Velasco et al., 2011), Ni/Sap catalysts for the hydrogenation of styrene oxide (Vicente et al., 2011), Co-Mo/Sap catalysts for upgrading squalene $\left(\mathrm{C}_{30} \mathrm{H}_{50}\right)$ (Garciano et al., 2014), $\mathrm{TiO}_{2} / \mathrm{Al}$-pillared Sap catalysts for photocatalytic phenol photo-oxidation (Fatimah and Wijaya, 2015), Ni/Zr-pillared Sap catalysts for hydrogenation of isopulegol (Fatimah et al., 2015), $\mathrm{TiO}_{2} /\left[\mathrm{Ru}(\mathrm{bpy})_{3}\right]^{2+}$-Sap catalysts for photocatalytic oxidation of benzene to phenol (Goto and Ogawa, 2015, 2016 ), ZnO/Sap catalysts for photodegradation of Methylene Blue (Khumchoo et al., 2016), Cu/Sap catalysts for soot combustion (Gebretsadik et al., 2016), and $\mathrm{Ni}$ (Gebretsadik et al., 2017b) and $\mathrm{MO}_{\mathrm{x}}$-modified nickel-copper catalysts (Gebretsadik et al., 2017a) supported on H-Sap for glycidol hydrogenolysis (Table 4). Saponite-supported catalysts are much stable even under irradiation and acid conditions (Khumchoo et al., 2016). In addition, a more recent study form Gebretsadik et al. (2017b) indicated that the acidity of H-Sap is conducive to the dispersion and reduction of $\mathrm{NiO}$ catalyst on the surface of $\mathrm{H}-\mathrm{Sap}$. The $\mathrm{NiO}$ and $\mathrm{Ni}$ particles could play a role in changing the amount and strength of surface acid sites of the Ni /Sap (Gebretsadik et al., 2017a). As proved by many reactions, there are indeed interactions between Sap support and metal atoms or metal oxides and the two can have a synergistic catalytic effect. However, the details remain unclear.

\subsection{Polymer additives}

Recently, Sap and organo-Sap has been used as reinforcing fillers in CPN (Table 3). Basically, it has been considered to possess the same functions as Mt nanolayers. By contrast, Sap could be more 
easily dispersed in the polymer matrix. Compared with pure polymers, CPN exhibit remarkable improvement in mechanical strength, Young's modulus, gas barrier properties, thermal stability, and water resistance (Zhen et al., 2012; Jairam et al., 2013; Yang et al., 2013; Zhen and Wang, 2016). The enhancement of those properties of the CPN is commonly ascribed to the existence of well-dispersed Sap nanolayers with a high aspect ratio in the CPN (Chang et al., 2014; Zhen and Wang, 2016).

In addition, Sap can act as a heterogeneous nucleating agent and accelerate the crystallization rate of polymers (Xi et al., 2015; Zhen and Wang, 2016). When the crystallization is improved, it also helps improve the thermal stability of the CPN (Zhen et al., 2014; Zhen and Zheng, 2016). Furthermore, during the in situ polymerization process, Sap can act as a green catalyst which catalyzes the polymerization reactions. Besides, Sap as adsorbents can contribute to adsorbing and eliminating the toxic chemicals during the polymerization process (Zhen et al., 2014; Zhen and Zheng, 2016). More recently, the CPN have been endowed with antibacterial properties. (Xi et al., 2015; Bandla et al., 2017). This broadens the functions of Sap and the application of the CPN.

It is noteworthy that the amount of Sap in the polymer matrix has a significant effect on the properties of the resultant Sap/polymer nanocomposite. In many cases, the addition of a small amount of Sap is sufficient to improve the thermal and mechanical properties and gas barrier. For example, Chang et al. (2014) found that for even 3-10 wt.\% Sap in the PVA matrix, the CPN exhibited much higher transition temperature than pure PVA. Ju and Chang (2016) found that upon the addition of Sap into PI matrix up to a critical loading amount of Sap (20 wt.\%), the glass transition temperatures $\left(\mathrm{T}_{\mathrm{g}}\right)$ and the initial thermal degradation temperature $\left(\mathrm{Ti}_{D}^{i}\right)$ of the Sap/PI hybrid films were remarkably improved. Nevertheless, the coefficient of thermal expansion (CTE) decreased. If Sap was added more than the critical content, the thermal properties worsened. Wu et al. (2014) found that the Sap/TOCN nanocomposite with $10 \mathrm{wt} . \%$ Sap exhibited the Young's modulus of $14.5 \mathrm{GPa}$, tensile strength of 425 MPa, and strain-to-failure of $10.2 \%$. Due to the addition of rigid Sap, the resistance to fracture of the Sap/TOCN nanocomposite increased more than sevenfold when the loading amount of Sap is increased from 0 to $10 \mathrm{wt} . \%$. Finally, it is worth mentioning that Sap is not always just an additive for polymers. In some cases, both the polymer and Sap are main components of the CPN, in particular as it is in the hybrid films (Zhou et al., 2011). In addition, Sap can be the main component and the polymers could be used with a lower amount to improve some functions (Shin et al., 2013). 


\section{Concluding remarks and future work}

Last decade has witnessed great ad advances in modification and hybridization spanning from simple interaction and surface engineering to fabrication of nanocomposite and hierarchical assembly. The researchers have smartly developed many strategies for introducing functional inorganic, organic and organic-inorganic guests into the interlayer space of Sap. In addition to acid activation, inorganic cation exchange, pillaring and catalyst supporting, the nanoscale interlayer space of Sap is increasingly being considered as a nanoreactor to produce a functional metal or metal oxide nanoparticle/Sap hybrid with magnetic, selective adsorptive and catalytic properties. Besides OSap and CPN, organically modified Sap and polymers can be made into functional films and such materials show promising applications in optics, biological and medical materials.

Undoubtedly, the great strides in the approaches to the modification and hybridization of Sap, along with the upsurge of inorganic nanotechnology and the discovery of functional organic molecules, provide many opportunities to use Sap for producing advanced materials. Meanwhile, previous studies have highlighted some challenges and problems which need laddering, as prudently and briefly remarked as follows:

(1) To the best of our knowledge, Sap is a scarce natural resource and is not as abundant as Mt; At present, the synthesis, modification and applications of Sap or the related studies is still limited on a laboratory scale. In order to scale up the modification and application of Sap, some critical issues need to be resolved. For example, a cleaner, efficient and profitable process of synthetic Sap should be first developed. For the modification of Sap, the wastewater and the toxic solvents need handling properly. In most cases, successful modification of Sap is usually a multiple-step process, which is time-consuming and cost-intensive. A good alternative way could be to integrate the synthesis with the modification of Sap. The one-pot reaction significantly shortens the process and simplifies the procedure, thereby lowering the cost. A few studies have shed new light on this technology. However, it is unknown if many other organic species can be introduced into the Sap in this way. Alternatively, a supercritical continuous flow process could worth be applied to synthesize and modify Sap. Such intensified process can improve mixing of reactants, mass and heat transfer and accordingly shorten the reaction and improve productivity. 
(2) Although the methods of modifying Sap have been greatly expanded, few studies provide the mechanisms, thermodynamics, and kinetics. Theoretically, molecular dynamics simulations and experimental cryo-electron microscopy (cryo-EM) and other scientific tools are helping throw new light on the mechanisms. In order to get a better understanding of the modification and scale up the relevant process, detailed investigations and data for engineering are of basic necessity.

(3) There is a need to put Sap and Sap-based materials onto the practice in industry. A critical issue is to modify Sap with functional species with the practical applications. As Sap is a good player in the hydrogel system, a combination of magnetic nanoparticles with Sap to produce magnetic nanoparticles/Sap hydrogel can bring exceptional properties in magnetism, rheology, adsorption, catalysis, and biocompatibility. Thus, the clay-based nanocomposites have potential to be applied in electromagnetic devices, magnetorheological fluids/ferrofluids, magnetic adsorbents, catalysts, biomaterials, biomedicines or highly simulated robots. In addition, there are various choices of functional guest species that exhibit exceptional biological, electrical, and optical properties and could to be introduced into Sap to produce new functional materials.

\section{Acknowledgments}

The authors wish to acknowledge the financial support from the National Natural Scientific Foundation of China (41672033; 21373185), the financial support by the open fund from Key Laboratory of Clay Minerals of Ministry of Land and Resources of the People's Republic of China, Engineering Research Center of Non-metallic Minerals of Zhejiang Province, Zhejiang Institute of Geology and Mineral Resource, China (ZD2018K05), and the State Key Laboratory Breeding Base of Green Chemistry-Preparation Technology, Zhejiang University of Technology (GCTKF2014006). Our thanks to all of anonymous 6 reviewers and EIC Dr F. Bergaya for the comments and suggestions that do help us improve the work much. QZ merely drafted the manuscript under the supervision of $\mathrm{CHZ}$ and then did not join any work for revision of two times after peer review. $\mathrm{CHZ}$ conceived the work and completely rewrote the text for the revision. QQW contributed much to drawing illustrations. Thanks for XCJ for helping apply to the relevant original publishers for the permissions of reprinting Figures where necessary.

\section{References}

Adraa, K. E., Georgelin, T., Lambert, J. F., Jaber, F., Tielens, F., Jaber, M., 2017. Cysteine-montmorillonite composites for heavy metal cation complexation: a combined experimental and theoretical study. Chemical Engineering Journal, 314, 406-417.

Albeniz, S., Vicente, M. A., Trujillano, R., Korili, S. A., Gil, A., 2014. Synthesis and characterization of organosaponites. Thermal behavior of their poly (vinyl chloride) nanocomposites. Applied Clay Science, 99, 72-82.

Baldermann, A., Dohrmann, R., Kaufhold, S., Nickel, C., Letofsky-Papst, I., Dietzel, M., 2014. The Fe-Mg-saponite solid solution series-a hydrothermal synthesis study. Clay Minerals, 49(3), 391-415.

Bandla, M., Abbavaram, B. R., Kokkarachedu, V., Sadiku, R. E., 2017. Silver nanoparticles incorporated within intercalated clay/polymer nanocomposite hydrogels for antibacterial studies. Polymer Composites, 38(S1), E16-E23

Belušáková, S., Lang, K., Bujdák, J., 2015. Hybrid systems based on layered silicate and organic dyes for cascade energy transfer. The Journal of Physical Chemistry C, 119(38), 21784-21794.

Belušáková, S., Martínez-Martínez, V., Arbeloa, I. L., Bujdak, J., 2017. Resonance Energy Transfer between Dye Molecules in 
Colloids of a Layered Silicate. The Effect of Dye Surface Concentration. The Journal of Physical Chemistry C, 121(15), 8300-8309.

Bergaoui, L., Lambert, J. F., Franck, R., Suquet, H., Robert, J. L., 1995a. Al-pillared saponites. part 3. - effect of parent clay layer charge on the intercalation. Journal of the Chemical Society Faraday Transactions, 91(14), 2229-2239.

Bergaoui, L., Lambert, J. F., Vicenterodriguez, M. A., Michot, L. J., Villieras, F., 1995b. Porosity of synthetic saponites with variable layer charge pillared by $\mathrm{Al}_{13}$ polycations. Langmuir, 11(8), 2849-2852.

Bhatnagar, A., Sillanpää, M., 2010. Utilization of agro-industrial and municipal waste materials as potential adsorbents for water treatment - a review. Chemical Engineering Journal, 157(2), 277-296.

Bian, L., Dong, F. Q., Song, M. X., Dong, H. L., Li, W. M., \& Duan, T., Xu, J. B., Zhang, X. Y., 2015. DFT and two-dimensional correlation analysis methods for evaluating the $\mathrm{Pu}^{3+}-\mathrm{Pu}^{4+}$ electronic transition of plutonium-doped zircon. Journal of Hazardous Materials, 294(8), 47-56.

Bian, L., Song, M. X., Dong, F. Q., Duan, T., Xu, J. B., Li, W. M., Zhang, X. Y., 2015. DFT and two-dimensional correlation analysis for evaluating the oxygen defect mechanism of low- density $4 \mathrm{f}$ (or $5 \mathrm{f}$ ) elements interacting with Ca-Mt. RSC Advances, 5, 28601-28610.Bisio, C., Carniato, F., Paul, G., Gatti, G., Boccaleri, E., Marchese, L., 2011. One-pot synthesis and physicochemical properties of an organo-modified saponite clay. Langmuir, 27(11), 7250-7257.

Bisio, C., Gatti, G., Boccaleri, E., Marchese, L., Bertinetti, L., Coluccia, S., 2008. On the acidity of saponite materials: a combined HRTEM, FTIR, and solid-state NMR study. Langmuir, 24(6), 2808-2819.

Boháč, P., Czímerová, A., Bujdák, J., 2016. Enhanced luminescence of 3, 3'-diethyl-2, 2'-thiacyanine cations adsorbed on saponite particles. Applied Clay Science, 127, 64-69.

Brigatti, M. F., Galan, E., Theng, B. K. G., 2013, Structure and Mineralogy of Clay Minerals. In: Bergaya, F., Lagaly, G. (Eds.), Developments in Clay Science, Vol. 5, Handbook of Clay Science, Second Edition. Amsterdam, Elsevier, pp. 21-81.

Budnyak, T. M., Yanovska, E. S., Kichkiruk, O. Y., Sternik, D., Tertykh, V. A., 2016. Natural minerals coated by biopolymer chitosan: synthesis, physicochemical, and adsorption properties. Nanoscale Research Letters, 11(1), 492-503.

Budnyak, T., Tertykh, V., Yanovska, E., 2014. Chitosan immobilized on silica surface for wastewater treatment. Materials Science, 20(2), 177-182.

Bujdák, J., Ratulovská, J., Donauerová, A., Bujdáková, H., 2016. Hybrid materials based on luminescent alkaloid berberine and saponite. Journal of Nanoscience and Nanotechnology, 16(8), 7801-7804.

Calzaferri, G., 2012. Nanochannels: hosts for the supramolecular organization of molecules and complexes. Langmuir 28, 6216-6231.

Carniato, F., Bisio, C., Gatti, G., Boccaleri, E., Bertinetti, L., Coluccia, S., Monticelli, O., Marchese, L., 2009. Titanosilsesquioxanes embedded in synthetic clay as a hybrid material for polymer science. Angewandte Chemie, 121(33), 6175-6177.

Carniato, F., Bisio, C., Gatti, G., Guidotti, M., Sordelli, L., Marchese, L., 2011. Organic-Inorganic Hybrid Saponites Obtained by Intercalation of Titano - Silsesquioxane. Chemistry-An Asian Journal, 6(3), 914-921.

Carniato, F., Bisio, C., Psaro, R., Marchese, L., Guidotti, M., 2014. Niobium (V) saponite clay for the catalytic oxidative abatement of chemical warfare agents. Angewandte Chemie International Edition, 53(38), 10095-10098.

Carrado K.A., Decarreau A., Petit S., Bergaya F., Lagaly G., 2006. Synthetic clay minerals and purification of natural clays, Chapitre 4. In: Bergaya F., Theng B., Lagaly G. (Eds.), Developments in Clay Science, Vol. 1, Handbook of Clay Science, Elsevier, pp. 115-139.

Carraro, A., De Giacomo, A., Giannossi, M. L., Medici, L., Muscarella, M., Palazzo, L., Quaranta, V., Summa, V., Tateo, F., 2014. Clay minerals as adsorbents of aflatoxin M 1 from contaminated milk and effects on milk quality. Applied Clay Science, 88, 92-99.

Carter, D.L., Heilman, M.D., Gonzalez, C.L., 1965. Ethylene glycol monoethyl ether for determining surface area of silicate minerals. J. Soil Sci. 100, 356-360.

Casagrande, M., Storaro, L., Lenarda, M., Rossini, S., 2005. Solid acid catalysts from clays: Oligomerization of 1-pentene on Al-pillared smectites. Catalysis Communications, 6(8), 568-572.

Chang, J. H., Ham, M., Kim, J. C., 2014. Comparison of Properties of Poly (vinyl alcohol) Nanocomposites Containing Two Different Clays. Journal of nanoscience and nanotechnology, 14(11), 8783-8791.

Chen, L., Zhou,C.H., Fiore, S., Tong, D.S., Zhang,H., Li, C.S., Ji S.F.,, Yu, W.H., 2016. Functional magnetic nanoparticle/clay mineral nanocomposites: preparation, magnetism and versatile applications Applied Clay Science. 127-128, 143-163

Chevalier, S., Franck, R., Suquet, H., Lambert, J. F., Barthomeuf, D., 1994. Al-pillared saponites. part 1.- IR studies. Journal of the Chemical Society Faraday Transactions, 90(4), 667-674.

Crini, G., Badot, P. M., 2008. Application of chitosan, a natural aminopolysaccharide, for dye removal from aqueous solutions by adsorption processes using batch studies: a review of recent literature. Progress in polymer science, 33(4), 399-447.

Cruz-Guzmán, M., Celis, R., Hermosín, M. C., Koskinen, W. C., Nater, E. A., Cornejo, J., 2012. Heavy metal adsorption by montmorillonites modified with natural organic cations. Soil Science Society of America Journal, 70(1), 215-221.

Czímerová, A., Sas, S., Čeklovský, A., 2017. Unique solvatochromism of cyanine/saponite hybrid systems. Applied Clay Science, 198-203.

Dazas, B., Lanson, B., Delville, A., Robert, J.L., Komarmeni, S., Michot, L.J., Ferrage E., 2015. Influence of tetrahedral layer charge on the organization of interlayer water and ions in synthetic Na-saturated smectites. Journal of Physical Chemistry C, 119, 4158-4172.

De Paiva, L.B., Morales, A.R., Valenzuela Díaz, F.R., 2008. Organoclays: properties, preparation and applications. Applied Clay Science, 42, 8-24.

De Stefanis, A., Cafarelli, P., Gallese, F., Borsella, E., Nana, A., Perez, G., 2013. Catalytic pyrolysis of polyethylene: A comparison between pillared and restructured clays. Journal of Analytical and Applied Pyrolysis, 104, 479-484.

Ding, Z., Kloprogge, J. T., Frost, R. L., Lu, G. Q., Zhu, H. Y., 2001. Porous clays and pillared clays-based catalysts. Part 2: a review of the catalytic and molecular sieve applications. Journal of Porous Materials, 8(4), 273-293.

Donauerová, A., Bujdák, J., Smolinská, M., Bujdáková, H., 2015. Photophysical and antibacterial properties of complex systems 

Dong, F. Q., Bian, L., Song, M. X., Li, W. M., Duan, T., 2016. Computational investigation on the $\mathrm{f}^{\mathrm{n}} \rightarrow \mathrm{f}^{\mathrm{n}-1} \mathrm{~d}$ effect on the

Dzene, L., Verron, H., Delville, A., Michot, L.J., Robert, J.L., Tertre, E., Hubert, F., Ferrage, E., 2017. Influence of tetrahedral layer charge on the fixation of cesium in synthetic smectite. Journal of Physical Chemistry C, 121, 23422-23435.

Ebina, T., Mizukami, F., 2007. Flexible transparent clay films with heat - resistant and high gas - barrier properties. Advanced Materials, 19(18), 2450-2453

Eguchi, M., Momotake, M., Inoue, F., Oshima, T., Maeda, K., Higuchi, M., 2017. Inert Layered Silicate Improves the Electrochemical Responses of a Metal Complex Polymer. ACS Applied Materials \& Interfaces, 9(40), 35498-35503.

Epelde-Elezcano, N., Martínez-Martínez, V., Duque-Redondo, E., Temiño, I., Manzano, H., López-Arbeloa, I., 2016. Strategies for modulating the luminescence properties of pyronin Y dye-clay films: an experimental and theoretical study. Physical Chemistry Chemical Physics, 18(12), 8730-8738.

Fatimah, I., Rubiyanto, D., Huda, T., 2015. Preparation and Characterization of Ni/Zr-Saponite as Catalyst in Catalytic Hydrogen Transfer Reaction of Isopulegol. In Materials Science Forum (Vol. 827, pp. 311-316). Trans Tech Publications.

Fatimah, I., Rubiyanto, D., Huda, T., Zuhrufa, Z., Yudha, S. P., Kartika, N. C., 2016. Novel sulphated zirconia pillared clay nanoparticles as catalyst in microwave assisted conversion of citronellal. Materials Technology, 31(4), 222-228.

Fatimah, I., Wijaya, K., 2015. Microwave assisted preparation of $\mathrm{TiO}_{2} / \mathrm{Al}$-pillared saponite for photocatalytic phenol photo-oxidation in aqueous solution. Arabian Journal of Chemistry, 8(2), 228-232.

Ferrage, E., 2016. Investigation of the interlayer organization of water and ions in smectite from the combined use of diffraction experiments and molecular simulations. A review of methodology, applications, and perspectives. Clays and Clay Minerals, 64, 346-371.

Ferrage, E., Lanson, B., Michot, L.J., Robert J.L., 2010. Hydration properties and interlayer organization of water and ions in synthetic Na-smectite with tetrahedral layer charge. Part 1. Results from X-ray diffraction profile modeling. Journal of Physical Chemistry C, 114, 4515-4526.

Franco, F., Benítez-Guerrero, M., Gonzalez-Triviño, I., Pérez-Recuerda, R., Assiego, C., Cifuentes-Melchor, J., Pascual-Cosp, J., 2016a. Low-cost aluminum and iron oxides supported on dioctahedral and trioctahedral smectites: a comparative study of the effectiveness on the heavy metal adsorption from water. Applied Clay Science, 119, 321-332.

Franco, F., Pozo, M., Cecilia, J. A., Benítez-Guerrero, M., Lorente, M., 2016b. Effectiveness of microwave assisted acid treatment on dioctahedral and trioctahedral smectites. The influence of octahedral composition. Applied Clay Science, 120, 70-80.

Fujimura, T., Ramasamy, E., Ishida, Y., Shimada, T., Takagi, S., Ramamurthy, V., 2016. Sequential energy and electron transfer in a three-component system aligned on a clay nanosheet. Physical Chemistry Chemical Physics, 18(7), 5404-5411.

Garade, A. C., Biradar, N. S., Joshi, S. M., Kshirsagar, V. S., Jha, R. K., Rode, C. V., 2011. Liquid phase oxidation of p-vanillyl alcohol over synthetic Co-saponite catalyst. Applied Clay Science, 53(2), 157-163.

Garciano II, L. O., Tran, N. H., Kannangara, G. K., Milev, A. S., Wilson, M. A., Volk, H., 2014. Developing saponite supported cobalt-molybdenum catalysts for upgrading squalene, a hydrocarbon from the microalgae Botryococcus braunii. Chemical Engineering Science, 107, 302-310.

Gebrestadik, F. B., Llorca, J., Salagre, P., Cesteros, Y., 2017a. Hydrogenolysis of glycidol as an alternative route to obtain 1,3-propanediol selectively using $\mathrm{Mo}_{\mathrm{x}}$-modified nickel-copper catalysts supported on acid mesoporous saponite. Chemcatchem, 9(19), 3670-3680.

Gebretsadik, F. B., Cesteros, Y., Salagre, P., Giménez-Mañogil, J., Garcia-Garcia, A., Bueno-López, A., 2016, Potential of $\mathrm{Cu}$-saponite catalysts for soot combustion. Catalysis Science \& Technology, 6(2), 507-514.

Gebretsadik, F. B., Ruiz-Martinez, J., Salagre, P., Cesteros, Y., 2017b. Glycidol hydrogenolysis on a cheap mesoporous acid saponite supported Ni catalyst as alternative approach to 1, 3-propanediol synthesis. Applied Catalysis A: General, 538, 91-98. Gebretsadik, F. B., Salagre, P., Cesteros, Y., 2014. Use of polymer as template in microwave synthesis of saponite. Study of several factors of influence. Applied Clay Science, 87, 170-178.

Giakisikli, G., Anthemidis, A. N., 2013. Magnetic materials as sorbents for metal/metalloid preconcentration and/or separation. A review. Analytica chimica acta, 789, 1-16.

Gil, A., Gandia, L. M., Vicente, M. A., 2000. Recent advances in the synthesis and catalytic applications of pillared clays. Catalysis Reviews, 42(1-2), 145-212.

Gómez-Sanz, F., Morales-Vargas, M. V., González-Rodríguez, B., Rojas-Cervantes, M. L., Pérez-Mayoral, E., 2017. Acid clay minerals as eco-friendly and cheap catalysts for the synthesis of $\beta$-amino ketones by Mannich reaction. Applied Clay Science, $143,250-257$.

Goto, T., Ogawa, M., 2015. Visible-light-responsive photocatalytic flow reactor composed of titania film photosensitized by metal complex-clay hybrid. Acs Applied Materials \& Interfaces, 7(23), 12631-12634

Goto, T., Ogawa, M., 2016. Efficient photocatalytic oxidation of benzene to phenol by metal complex-clay/ $\mathrm{TiO}_{2}$ hybrid photocatalyst. Rsc Advances, 6(28), 23794-23797.

Guidotti, M., Psaro, R., Ravasio, N., Sgobba, M., Carniato, F., Bisio, C., Gatti, G., Marchese, L., 2009. An efficient ring opening reaction of methyl epoxystearate promoted by synthetic acid saponite clays. Green Chemistry, 11(8), 1173-1178.

Gust, D., Moore, T.A., Moore, A.L., 2009. Solar fuels via artificial photosynthesis. Acc Chem Res, 42(12), 1890-1898.

Hashemian, S., Dehghanpor, A., Moghahed, M., 2015. $\mathrm{Cu}_{0.5} \mathrm{Mn}_{0.5} \mathrm{Fe}_{2} \mathrm{O}_{4}$ nano spinels as potential sorbent for adsorption of brilliant green. Journal of Industrial and Engineering Chemistry, 24, 308-314.

Hasobe, T., 2013. Porphyrin-based supramolecular nanoarchitectures for solar energy conversion. Journal of Physical Chemistry Letters, 4(11), 1771-1780.

He, H., Duchet, J., Galy, J., Gerard, J. F., 2005. Grafting of swelling clay materials with 3-aminopropyltriethoxysilane. Journal of colloid and interface science, 288(1), 171-176.

He, H.P., Li, T., Tao, Q., Chen, T.H., Zhang, D., Zhu, J.X., Yuan, P., Zhu, R.L., 2014. Aluminum ion occupancy in the structure of synthetic saponites: effect on crystallinity. American Mineralogist. 99(1), 109-116.

Herrera, N.N., Letoffe, J.M., Putaux, J.L., David, L., Bourgeat-Lami, E., 2004. Aqueous dispersions of silane-functionalized laponite clay platelets. A first step toward the elaboration of water-based polymer/clay nanocomposites. Langmuir 20 , $1564-1571$. 
Hosokawa, H., Mochida, T., 2015. Colorimetric Humidity and Solvent Recognition Based on a Cation-Exchange Clay Mineral Incorporating Nickel (II)-Chelate Complexes. Langmuir, 31(47), 13048-13053. Intachai, S., Khaorapapong, N., Ogawa, M., 2017. Hydrothermal synthesis of zinc selenide in smectites. Applied Clay Science, $135,45-51$

Ishida, Y., Kulasekharan, R., Shimada, T., Takagi, S., Ramamurthy, V., 2013. Efficient Singlet-Singlet Energy Transfer in a Novel Host-Guest Assembly Composed of an Organic Cavitand, Aromatic Molecules, and a Clay Nanosheet. Langmuir, 29(6), 1748-1753.

Jaber, M., Komarneni, S., Zhou, C.H., 2013.Chapter 7.2, Synthesis ofclay minerals. In: Bergaya, F., Lagaly, G. (Eds.), Developments in Clay Science, Vol. 5, Handbook of Clay Science(second Edition), Part A. Amsterdam, Elsevier

Jairam, S., Tong, Z., Wang, L., Welt, B., 2013. Encapsulation of a biobased lignin-saponite nanohybrid into polystyrene co-butyl acrylate (PSBA) latex via miniemulsion polymerization. ACS Sustainable Chemistry \& Engineering, 1(12), 1630-1637.

Ju, J., Chang, J. H., 2016. Comparison of the properties of colorless polyimide nanocomposites containing saponite or organically modified hectorite. Journal of Thermoplastic Composite Materials, 29(4), 558-576.

Kameshima, Y., Kageyama, K., Mizunuma, Y., Komatsu, T., Isobe, T., Nakajima, A., Okada, K., 2013. Preparation and solid acidity of zirconia-cluster/saponite composites. Journal- Ceramic Society Japan, 121(1409), 49-53.

Kannan, V., Sreekumar, K., Gil, A., Vicente, M. A., 2011. Acetalation of pentaerithritol catalyzed by an Al-pillared saponite. Catalysis letters, 141(8), 1118-1122.

Kaviratna, H., Pinnavaia, T. J. (1994). Acid hydrolysis of octahedral $\mathrm{Mg}^{2+}$ sites in 2: 1 layered silicates: An assessment of edge attack and gallery access mechanisms. Clays and Clay Minerals, 42(6), 717-723.

Khumchoo, N., Khaorapapong, N., Ogawa, M., 2015. Formation of zinc oxide particles in cetyltrimethylammonium-smectites. Applied Clay Science, 105-106, 236-242.

Khumchoo, N., Khaorapapong, N., Ontam, A., Intachai, S., Ogawa, M., 2016. Efficient Photodegradation of Organics in Acidic Solution by ZnO-Smectite Hybrids. European Journal of Inorganic Chemistry, 2016(19), 3157-3162.

Kim, Y., Kirkpatrick, R. J., 1997. ${ }^{23} \mathrm{Na}$ and ${ }^{133} \mathrm{Cs}$ NMR study of cation adsorption on mineral surfaces: local environments, dynamics, and effects of mixed cations. Geochimica Et Cosmochimica Acta, 61(24), 5199-5208.

Kitajima, S., Bertasi, F., Vezzù, K., Negro, E., Tominaga, Y., Di Noto, V., 2013. Dielectric relaxations and conduction mechanisms in polyether-clay composite polymer electrolytes under high carbon dioxide pressure. Physical Chemistry Chemical Physics, 15(39), 16626-16633.

Kloprogge, J. T., S. Komarneni and J. E. Amonette, 1999. Synthesis of Smectite Clay Minerals: A Critical Review, Clays Clay Miner. 47:529-554

Komadel, P., Madejová, J., 2013. Acid activation of clay minerals. In: Bergaya, F., Lagaly, G. (Eds.), Developments in Clay Science, Vol. 5, Handbook of Clay Science, Second Edition. Amsterdam, Elsevier, pp. 385-409.

Konno, S., Fujimura, T., Otani, Y., Shimada, T., Inoue, H., Takagi, S., 2014. Microstructures of the porphyrin/viologen monolayer on the clay surface: segregation or integration.. Journal of Physical Chemistry C, 118(35), 20504-20510.

Kotal, M., Bhowmick, A. K., 2015. Polymer nanocomposites from modified clays: Recent advances and challenges. Progress in Polymer Science, 51, 127-187.

Kurokawa, H., Hayasaka, M., Yamamoto, K., Sakuragi, T., Ohshima, M. A., Miura, H., 2014. Self-assembled heterogeneous late transition-metal catalysts for ethylene polymerization; New approach to simple preparation of iron and nickel complexes immobilized in clay mineral interlayer. Catalysis Communications, 47, 13-17.

Lagaly, G., 1981. Characterization of clays by organic compounds. Clay Minerals. 16, 1-21.

Lagaly, G., 1986. Interaction of alkyamines with differents types of layered compounds. Solid State Ionics 22, 43-51.

Lagaly, G., Weiss, A., 1969. Determination of the layer charge in mica-type layer silicates. In Proceedings of the International Clay Conference, Tokyo (Vol. 1, pp. 61-80). Israel University Press, Jerusalem.

Lainé, M., Balan, E., Allard, T., Paineau, E., Jeunesse, P., Mostafavi, M., Robert, J.-L., Le Caër, S., 2017. Reaction mechanisms in swelling clays under ionizing radiation: influence of the water amount and of the nature of the clay mineral. RSC Advances, 7(1), 526-534.

Lambert, J. F., Chevalier, S., Franck, R., Suquet, H., Barthomeuf, D., 1994. Al-pillared saponites. part 2.-NMR studies. Journal of the Chemical Society Faraday Transactions, 90(4), 675-682.

Lambert and Bergaya, 2013. Smectite Polymer Nanocomposites (Chapter 13.1). In: Bergaya and Lagaly, Eds. Handbook of Clay Science Vol. 5A, Developments of Clay Science, Elsevier

Makarchuk, O. V., Dontsova, T. A., Astrelin, I. M., 2016. Magnetic nanocomposites as efficient sorption materials for removing dyes from aqueous solutions. Nanoscale Research Letters, 11(1), 161-168

Malla, P. B. and S. Komarneni, "Properties and Characterization of $\mathrm{Al}_{2} \mathrm{O}_{3}$ and $\mathrm{SiO}_{2}-\mathrm{TiO}_{2}$ Pillared Saponite as Affected by Pillaring", Clays Clay Miner. 41: 472-483 (1993).

Marcal, L., de Faria, E. H., Nassar, E. J., Trujillano, R., Martin, N., Vicente, M. A., Rives, V., Gil, A., Korili, S.A., Ciuffi, K. J., 2015. Organically modified saponites: SAXS study of swelling and application in caffeine removal. ACS applied materials \& interfaces, 7(20), 10853-10862.

Matejdes, M., Himeno, D., Suzuki, Y., Kawamata, J., 2017. Controlled formation of pseudoisocyanine J-aggregates in the interlayer space of synthetic saponite. Applied Clay Science, 140, 119-123.

Mcbride, M. B., 1994. Environmental chemistry of soils. Environmental chemistry of soils. Oxford University Press, 1-146.

McLaurin, E.J., Bradshaw, L.R., Gamelin, D.R., 2013. Dual-emitting nanoscale temperature sensors. Chem. Mater. 25, $1283-1292$.

Migal', E. A., Mishchenko, M. D., Ozheredov, I. A., Postnova, I. V., Sapozhnikov, D. A., Shkurinov, A. P., Shchipunov, Y. A., 2016. A terahertz spectroscopic study of chitosan-based bionanocomposites containing clay nanoparticles. Colloid Journal, 78(2), 189-195.

Miyagawa, M., Shibusawa, A., Maeda, K., Tashiro, A., Sugai, T., Tanaka, H., 2017. Diameter-controlled Cu nanoparticles on saponite and preparation of film by using spontaneous phase separation. RSC Advances, 7(66), 41896-41902.

Momma, K., Izumi, F., 2011. VESTA 3 for three-dimensional visualization of crystal, volumetric and morphology data. Journal of Applied Crystallography, 44(6), 1272-1276.

Nakamura, T., Ogawa, M., 2013. Adsorption of cationic dyes within spherical particles of poly ( $\mathrm{N}$-isopropylacrylamide) hydrogel containing smectite. Applied Clay Science, 83, 469-473.

Nanan, S., Khumchoo, N., Intachai, S., Khaorapapong, N., 2015. A hybrid of hexakis (hexyloxy) triphenylene and synthetic 
saponite. Applied Clay Science, 114, 407-411.

Nityashree, N., Gautam, U. K., Rajamathi, M., 2014. Synthesis and thermal decomposition of metal hydroxide intercalated saponite. Applied Clay Science, 87, 163-169.

Ogawa, M., Kuroda, K., 1997. Preparation of inorganic-organic nanocomposites through intercalation of organoammonium ions into layered silicates. Bulletin of the Chemical Society of Japan, 70(11), 2593-2618.

Ogawa, M., Takee, R., Okabe, Y., Seki, Y., 2017. Bio-geo hybrid pigment; clay-anthocyanin complex which changes color depending on the atmosphere. Dyes \& Pigments, 139, 561-565.

Okada, T., Oguchi, J., Yamamoto, K. I., Shiono, T., Fujita, M., Iiyama, T., 2015. Organoclays in water cause expansion that facilitates caffeine adsorption. Langmuir, 31(1), 180-187.

Olaya, A., Moreno, S., Molina, R., 2009. Synthesis of pillared clays with aluminum by means of concentrated suspensions and microwave radiation. Catalysis Communications, 10(5), 697-701.

Olivero, F., Carniato, F., Bisio, C., Marchese, L., 2014. Promotion of Förster resonance energy transfer in a saponite clay containing luminescent polyhedral oligomeric silsesquioxane and rhodamine dye. Chemistry-An Asian Journal, 9(1), 158-165.

Ostinelli, L., Recchia, S., Bisio, C., Carniato, F., Guidotti, M., Marchese, L., Psaro, R., 2012. Acid/vanadium - containing saponite for the conversion of propene into coke: potential flame - retardant filler for nanocomposite materials. Chemistry-An Asian Journal, 7(10), 2394-2402.

Padilla-Ortega, E., Darder, M., Aranda, P., Figueredo Gouveia, R., Leyva-Ramos, R., RuizHitzky, E., 2016. Ultrasound assisted preparation of chitosan-vermiculite bionanocomposite foams for cadmium uptake. Applied Clay Science. 130, 40-49.

Pandey, J. K., Reddy, K. R., Kumar, A. P., Singh, R. P., 2005. An overview on the degradability of polymer nanocomposites. Polymer degradation and stability, 88(2), 234-250.

Paul, D. R., Robeson, L. M., 2008. Polymer nanotechnology: nanocomposites. Polymer, 49(15), 3187-3204.

Petra, L., Billik, P., Melichová, Z., Komadel, P., 2017. Mechanochemically activated saponite as materials for $\mathrm{Cu}^{2+}$, and $\mathrm{Ni}^{2+}$ removal from aqueous solutions. Applied Clay Science, 143, 22-28.

Pigatto, G., Lodi, A., Finocchio, E., Palma, M. S., Converti, A., 2013. Chitin as biosorbent for phenol removal from aqueous solution: Equilibrium, kinetic and thermodynamic studies. Chemical Engineering and Processing: Process Intensification, 70, 131-139.

Pimchan, P., Khaorapapong, N., Ogawa, M., 2014. The effect of cetyltrimethylammonium ion and type of smectites on the luminescence efficiency of bis(8-hydroxyquinoline)zinc(ii) complex. Applied Clay Science, 101, 223-228.

Rafatullah, M., Sulaiman, O., Hashim, R., Ahmad, A., 2010. Adsorption of methylene blue on low-cost adsorbents: a review. Journal of hazardous materials, 177(1), 70-80.

Rodriguez, M. V., González, J. D. D. L., Munoz, M. B., 1995. Preparation of microporous solids by acid treatment of a saponite. Microporous Materials, 4(4), 251-264.

Roelofs, J. C. A. A., Berben, P. H., 2006. Preparation and performance of synthetic organoclays. Applied clay science, 33(1), 13-20.

Sas, S., Danko, M., Bizovská, V., Lang, K., Bujdák, J., 2017. Highly luminescent hybrid materials based on smectites with polyethylene glycol modified with rhodamine fluorophore. Applied Clay Science, 138, 25-33.

Sato, H., Ochi, M., Kato, M., Tamura, K., Yamagishi, A., 2014a. Energy transfer in hybrid langmuir-blodgett films of iridium complexes and synthetic saponite: dependence of transfer efficiency on interlayer distance. New Journal of Chemistry, 38(12), 5715-5720

Sato, H., Tamura, K., Taniguchi, M., Yamagishi, A., 2014b. Efficient energy transfer of cationic iridium (III) complexes on the surface of a colloidal clay. Applied Clay Science, 97, 84-90.

Sato, K., Fujimoto, K., Dai, W., Hunger, M., 2016. Quantitative Elucidation of Cs Adsorption Sites in Clays: Toward Sophisticated Decontamination of Radioactive Cs. The Journal of Physical Chemistry C, 120(2), 1270-1274.

Sato, K., Hunger, M., 2017. Molecular studies of Cs adsorption sites in inorganic layered materials: the influence of solution concentration. Physical Chemistry Chemical Physics, 19(28), 18481-18486.

Seki, Y., Ide, Y., Okada, T., Ogawa, M. 2015. Concentration of 2-phenylphenol by organoclays from aqueous sucrose solution. Applied Clay Science, 109, 64-67.

Seki, Y., Ogawa, M., 2010. The removal of 2-phenylphenol from aqueous solution by adsorption onto organoclays. Bulletin of the Chemical Society of Japan, 83(6), 712-715.

Shchipunov, Y. A., Sarin, S. A., Silant'ev, V. E., Postnova, I. V., 2012a. Self-organization in the chitosan-clay nanoparticles system regulated through polysaccharide macromolecule charging. 2. Films. Colloid Journal, 74(5), 636-644.

Shchipunov, Y. A., Silant'ev, V. E., Postnova, I. V., 2012b. Self-organization in the chitosan-clay nanoparticles system regulated through polysaccharide macromolecule charging. 1. Hydrogels. Colloid Journal, 74(5), 627-635.

Shchipunov, Y., Ivanova, N., Silant'ev, V., 2009. Bionanocomposites formed by in situ charged chitosan with clay. Green Chemistry, 11(11), 1758-1761.

Shchipunov, Y., Postnova, I., 2010. Water-soluble polyelectrolyte complexes of oppositely charged polysaccharides. Composite Interfaces, 16(4-6), 251-279.

Shen, Z., Simon, G. P., Cheng, Y. B., 2002. Comparison of solution intercalation and melt intercalation of polymer-clay nanocomposites. Polymer, 43(15), 4251-4260.

Shin, J., Kim, J. C., Chang, J. H., 2013. Flexible clay hybrid films with various poly (vinyl alcohol) contents: Thermal properties, morphology, optical transparency, and gas permeability. Macromolecular Research, 21(12), 1349-1354.

Srinivasan, R., 2011. Advances in application of natural clay and its composites in removal of biological, organic, and inorganic contaminants from drinking water. Advances in Materials Science \& Engineering, 2011(1), 1-5.

Suquet, H., Iiyama, J.T., Kodama, H., Pezerat, H., 1977. Synthesis and swelling properties of saponites with increasing layer charge. Clays and Clay Mienrals, 25, 231-242.

Suquet, H., Malard, C., Copin, E., Pezerat, H., 1981. Variation du paramètre b et de la distance basale $\mathrm{d}_{001}$ dans une série de saponites à charge croissante: I Etats hydratés. Clay Minerals, 16(1), 53-67.

Suzuki, Y., Sugihara, H., Satomi, K., Tominaga, M., Mochida, S., Kawamata, J., 2014. Two-photon absorption properties of an acetylene derivative confined in the interlayer space of a smectite. Applied Clay Science, 96(26), 116-119.

Takagi, S., Shimada, T., Ishida, Y., Fujimura, T., Masui, D., Tachibana, H., Eguchi, M., Inoue, H., 2013. Size-matching effect on inorganic nanosheets: control of distance, alignment, and orientation of molecular adsorption as a bottom-up methodology for nanomaterials. Langmuir, 29(7), 2108-2119.

Tamura, K., Yamagishi, A., Kitazawa, T., Sato, H., 2015. Harvesting light energy by iridium(iii) complexes on a clay surface. Physical Chemistry Chemical Physics, 17(28), 18288

Tangaraj, V., Janot, J. M., Jaber, M., Bechelany, M., Balme, S., 2017. Adsorption and photophysical properties of fluorescent 
dyes over montmorillonite and saponite modified by surfactant. Chemosphere, 184, 1355-1361.

Tao, Q., Fang, Y., Li, T., Zhang, D., Chen, M.Y., Ji, S.C., He, H.P., Komarneni, S., Zhang, H.B., Dong, Y., Noh, Y. D., 2016. Silylation of saponite with 3-aminopropyltriethoxysilane. Applied Clay Science, 132, 133-139.

Theng, B. K. G., 1974. The Chemistry of Clay-Organic Reactions. The chemistry of clay-organic reactions. Hilger.

Tokieda, D., Tsukamoto, T., Ishida, Y., Ichihara, H., Shimada, T., Takagi, S., 2017. Unique fluorescence behavior of dyes on the clay minerals surface: surface fixation induced emission (s-fie). Journal of Photochemistry \& Photobiology A Chemistry, 339, $67-79$.

Tominaga, M., Nishioka, Y., Tani, S., Suzuki, Y., Kawamata, J., 2017. Tunable high-pressure field operating on a cationic biphenyl derivative intercalated in clay minerals. Scientific Reports, 7(1), 7651.

Tominaga, M., Oniki, Y., Mochida, S., Kasatani, K., Tani, S., Suzuki, Y., Kawamata, J., 2016. Clay-Organic Hybrid Films Exhibiting Reversible Fluorescent Color Switching Induced by Swelling and Drying of a Clay Mineral. The Journal of Physical Chemistry C, 120(41), 23813-23822.

Tong, Z., Deng, Y., 2013. The formation of asymmetric polystyrene/saponite composite nanoparticles via miniemulsion polymerization. Journal of Applied Polymer Science, 127(5), 3916-3922.

Trujillano, R., Rico, E., Vicente, M. A., Herrero, M., Rives, V., 2010. Microwave radiation and mechanical grinding as new ways for preparation of saponite-like materials. Applied Clay Science, 48(1), 32-38.

Trujillano, R., Rico, E., Vicente, M. A., Rives, V., Ciuffi, K. J., Cestari, A., Gil, A., Korili, S. A., 2011. Rapid microwave-assisted synthesis of saponites and their use as oxidation catalysts. Applied Clay Science, 53(2), 326-330.

Trujillano, R., Vicente, M. A., Rives, V., Korili, S. A., Gil, A., Ciuffi, K. J., Nassar, E. J., 2009. Preparation, alumina-pillaring and oxidation catalytic performances of synthetic Ni-saponite. Microporous and Mesoporous Materials, 117(1), 309-316.

Tsukamoto, T., Ramasamy, E., Shimada, T., Takagi, S., Ramamurthy, V., 2016a. Supramolecular surface photochemistry: cascade energy transfer between encapsulated dyes aligned on a clay nanosheet surface. Langmuir, 32(12), 2920-2927.

Tsukamoto, T., Shimada, T., Takagi, S., 2016b. Photophysical Properties and Adsorption Behaviors of Novel Tri-Cationic Boron (III) Subporphyrin on Anionic Clay Surface. ACS applied materials \& interfaces, 8(11), 7522-7528.

Ugochukwu, U. C., Fialips, C. I., 2017a. Crude oil polycyclic aromatic hydrocarbons removal via clay-microbe-oil interactions: Effect of acid activated clay minerals. Chemosphere, 178, 65-72.

Ugochukwu, U. C., Fialips, C. I., 2017b. Removal of crude oil polycyclic aromatic hydrocarbons via organoclay-microbe-oil interactions. Chemosphere, 174, 28-38.

Ugochukwu, U. C., Jones, M. D., Head, I. M., Manning, D. A., Fialips, C. I., 2014a. Effect of acid activated clay minerals on biodegradation of crude oil hydrocarbons. International Biodeterioration \& Biodegradation, 88, 185-191.

Ugochukwu, U. C., Manning, D. A.C., Fialips, C. I., 2014b. Microbial degradation of crude oil hydrocarbons on organoclay minerals. Journal of Environmental Management, 144, 197-202.

Utracki, L. A., Sepehr, M., Boccaleri, E., 2007. Synthetic, layered nano-particles for polymeric nanocomposites (PNC's). Polymers for Advanced Technologies, 18(1), 1-37.

Vdović, N., Jurina, I., Škapin, S.D., Sondi, I., 2010. The surface properties of clay minerals modified by intensive dry milling revisited. Applied Clay Science. 48, 575-580.

Velasco, J., Pérez-Mayoral, E., Mata, G., Rojas-Cervantes, M. L., Vicente-Rodríguez, M. A., 2011. Cesium-saponites as excellent environmental-friendly catalysts for the synthesis of N-alkyl pyrazoles. Applied Clay Science, 54(2), 125-131.

Venkatachalam, S., Hayashi, H., Ebina, T., Nakamura, T., Nanjo, H., 2013. Optoelectronic properties of nanostructured ZnO thin films prepared on glass and transparent flexible clay substrates by hydrothermal method. Japanese Journal of Applied Physics, 52(5), 492-494.

Verma, S., Ghosh, H.N., 2012. Exciton energy and charge transfer in porphyrin aggregate/semiconductor $\left(\mathrm{TiO}_{2}\right)$ composites. J. Phys. Chem. Lett. 3, 1877-1884.

Vicente, I., Salagre, P., Cesteros, Y., 2011. Ni nanoparticles supported on microwave-synthesised saponite for the hydrogenation of styrene oxide. Applied Clay Science, 53(2), 212-219.

Vicente, M. A., Belver, C., Sychev, M., Prihod'ko, R., Gil, A., 2008. Relationship between the surface properties and the catalytic performance of Al-, Ga-, and AlGa-pillared saponites. Industrial \& Engineering Chemistry Research, 48(1), 406-414.

Vicente, M. A., Gil, A., Bergaya, F., 2013. Pillared Clays and Clays Minerals. In: Bergaya, F., Lagaly, G. (Eds.), Developments in Clay Science, Vol. 5, Handbook of Clay Science, Second Edition. Amsterdam, Elsevier, pp. 523-557.

Vogels, R. J. M. J., Kloprogge, J. T., Geus, J. W., 2005. Synthesis and characterization of saponite clays. American Mineralogist, 90(5-6), 931-944.

Wang, W., Zhen, W., Bian, S., Xi, X., 2015. Structure and properties of quaternary fulvic acid-intercalated saponite/poly (lactic acid) nanocomposites. Applied Clay Science, 109, 136-142.

Wu, C. N., Yang, Q., Takeuchi, M., Saito, T., Isogai, A., 2014. Highly tough and transparent layered composites of nanocellulose and synthetic silicate. Nanoscale, 6(1), 392-399.

Wu, L., Lv, G., Liu, M., Li, Z., Liao, L., Pan, C., 2015. Adjusting the Layer Charges of Host Phyllosilicates To Prevent Luminescence Quenching of Fluorescence Dyes. The Journal of Physical Chemistry C, 119(39), 22625-22631.

Wu, L. M., Liao, L. B., Lv, G. C., 2015. Influence of interlayer cations on organic intercalation of montmorillonite. Journal

Colloid \& Interface Science, 454, 1-7.

Wysokowski, M., Klapiszewski, Ł., Moszyński, D., Bartczak, P., Szatkowski, T., Majchrzak, I., Siwinska-Stefanska, K., Bazhenov, V.V., Jesionowski, T., 2014. Modification of chitin with kraft lignin and development of new biosorbents for removal of cadmium (II) and nickel (II) ions. Marine drugs, 12(4), 2245-2268.

Wysokowski, M., Petrenko, I., Stelling, A. L., Stawski, D., Jesionowski, T., Ehrlich, H., 2015. Poriferan chitin as a versatile template for extreme biomimetics. Polymers, 7(2), 235-265.

Xi, X., Zhen, W., Bian, S., 2015. Preparation and properties of polylactic acid/N-(2-hydroxyl) propyl-3-trimethyl ammonium chitosan chloride-intercalated saponite nanocomposites. Iranian Polymer Journal, 24(3), 243-252.

Xu, P., Zeng, G. M., Huang, D. L., Feng, C. L., Hu, S., Zhao, M. H., Lai, C., Wei, Z., Huang, C., Xie, G.X., Liu, Z. F., 2012. Use of iron oxide nanomaterials in wastewater treatment: a review. Science of the Total Environment, 424, 1-10.

Yang, F., Sun, S., Chena, X., Chang, Y., Zha, F., Lei, Z., 2016. Mg-Al layered double hydroxides modified clay adsorbents for efficient removal of $\mathrm{Pb}^{2+}, \mathrm{Cu}^{2+}$ and $\mathrm{Ni}^{2+}$ from water. Applied Clay Science, 123, 134-140.

Yang, Q., Saito, T., Isogai, A., 2013. Transparent, flexible, and high - strength regenerated cellulose/saponite nanocomposite films with high gas barrier properties. Journal of Applied Polymer Science, 130(5), 3168-3174.

Yu, W.H., Ren, Q.Q., Tong, D.S., Zhou, C.H., Wang, H., 2014. Clean production of CTAB montmorillonite: formation 
mechanism and swelling behavior in xylene. Appl. Clay Sci. 97-98, 222-234.

Zhang, C. Q., He, H. P., Tao, Q., Ji, S. C., Li, S.Y., Ma, L. Y., Su, X. L., Zhu, J. X., 2017. Metal occupancy and its influence on thermal stability of synthetic saponites. Applied Clay Science, 135, 282-288.

Zhang, D., Zhou, C.H., Lin, C.X., Tong, D.S., Yu,W.H., 2010. Synthesis of clay minerals. Appl. Clay Sci. 50, 1-11. oxide pillared saponite nanocomposites. Polymer Composites, 35(6), 1023-1030. Zhen, W., Lu, C., Li, C., Liang, M., 2012. Structure and properties of thermoplastic saponite/poly (vinyl alcohol) nanocomposites. Applied Clay Science, 57, 64-70.

Zhen, W., Sun, J., 2014. Properties, structure and crystallization of poly lactic acid/zinc oxide pillared organic saponite nanocomposites. Polymer Korea, 38(3), 299-306.

Zhen, W., Wang, W., 2016. Structure, properties and rheological behavior of thermoplastic poly (lactic acid)/quaternary fulvic acid-intercalated saponite nanocomposites. Polymer Bulletin, 73(4), 1015-1035.

Zhen, W., Zheng, Y., 2016. Synthesis, characterization, and thermal stability of poly (lactic acid)/zinc oxide pillared organic saponite nanocomposites via ring - opening polymerization of D,L-lactide. Polymers for Advanced Technologies, 27(5), 606-614.

Zhou, C.H., 2011. An overview on strategies towards clay-based designer catalysts for green and sustainable catalysis. Appl. Clay Sci. 53, 87-96.

Zhou, C.H., Keeling, J.L., 2013. Fundamental and applied research on clay minerals: from climate and environment to nanotechnology. Appl. Clay Sci. 74, 3-9.

Zhou, C.H., Shen, Z.F., Liu, L.H., Liu, S.M., 2011a. Preparation and functionality of claycontaining films. J. Mater. Chem. 21, $15132-15153$.

Zhou, C.H., Xia, X., Lin, C.X., Tong, D.S., Beltramini, J.,Zhu, R., Chena, Q., Zhou, Q., Xi, Y., Zhu, J., He, H., 2016. Adsorbents based on montmorillonite for contaminant removal from water: a review. Applied Clay Science, 123, 239-258.

Zou, H., Wu, S., Shen, J., 2008. Polymer/silica nanocomposites: preparation, characterization, properties, and applications. Chemical Review, 108(9), 3893-3957. 